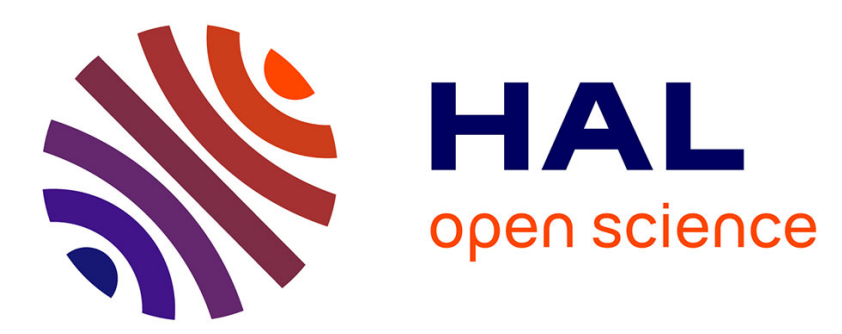

\title{
Counterion of chitosan influences thermodynamics of association of siRNA with a chitosan-based siRNA carrier
}

Christelle Zandanel, Magali Noiray, Christine Vauthier

\section{To cite this version:}

Christelle Zandanel, Magali Noiray, Christine Vauthier. Counterion of chitosan influences thermodynamics of association of siRNA with a chitosan-based siRNA carrier. Pharmaceutical Research, 2020, 37 (2), 10.1007/s11095-019-2751-z . hal-02984004

\author{
HAL Id: hal-02984004 \\ https://hal.science/hal-02984004
}

Submitted on 30 Oct 2020

HAL is a multi-disciplinary open access archive for the deposit and dissemination of scientific research documents, whether they are published or not. The documents may come from teaching and research institutions in France or abroad, or from public or private research centers.
L'archive ouverte pluridisciplinaire HAL, est destinée au dépôt et à la diffusion de documents scientifiques de niveau recherche, publiés ou non, émanant des établissements d'enseignement et de recherche français ou étrangers, des laboratoires publics ou privés. 


\section{Counterion of chitosan influences thermodynamics of association of siRNA with a chitosan-based siRNA carrier.}

Christelle Zandanel${ }^{1}$; Magali Noiray ${ }^{1}$; Christine Vauthier ${ }^{1 *}$

${ }^{1}$ Université Paris-Saclay, Institut Galien Paris-Saclay, CNRS UMR 8612, 5 rue J.B. Clément, 92296 ChâtenayMalabry Cedex, France

Running title: Chitosan salt influences thermodynamics of association with siRNA

Published in: Pharm Res. 2020 Jan 2;37(2):22. doi: 10.1007/s11095-019-2751-z.

* corresponding author

Christine VAUTHIER

Institut Galien Paris-Saclay, CNRS UMR 8612,

Univ Paris-Saclay, Faculté de Pharmacie,

5 rue J.B. Clément, 92296 Chatenay Malabry (France)

Telephone: + 331468356 03; Fax: + 33146835312

E-mail: christine.vauthier@u-psud.fr 


\begin{abstract}
Purpose: The work aimed to compare quality of a siRNA carrier prepared with chitosan of two different sources having similar degree of deacetylation and molecular weights. Differences were analyzed from thermodynamic characteristics of interactions with siRNA. Methods: The siRNA carrier (chitosan-coated poly(isobutylcyanoacrylate) nanoparticles) was prepared with home-prepared, $\mathrm{CS}_{\mathrm{Lab}}$, and commercial, $\mathrm{CS}_{\mathrm{Com}}$, chitosans. Chitosan counterion was identified and chitosans $\mathrm{CS}_{\text {commod} 1}$ and $\mathrm{CS}_{\mathrm{com}} \bmod 2$ were obtained from $\mathrm{CS}_{\text {com }}$ exchanging counterion with that found on $\mathrm{CS}_{\text {Lab }}$. Carrier quality was checked considering the size, zeta potential and siRNA association capacity by gel electrophoresis. Thermodynamic parameters of interactions between siRNA and chitosans in solution or immobilized at the carrier surface were determined by (ITC). Results: $\mathrm{CS}_{\mathrm{Lab}}$ and $\mathrm{CS}_{\mathrm{Com}} \bmod 2$ having a high content of acetate counterion associated better siRNA than $\mathrm{CS}_{\mathrm{Com}}$ and $\mathrm{CS}_{\mathrm{com} m o d 1}$ which counterion included mainly chloride. ITC measurements indicated that siRNA interactions with chitosan and the siRNA carrier were driven by entropic phenomena including dehydration, but thermodynamic parameters of interactions clearly differed according to the nature of the counterion of chitosan. The influence of chitosan counterions was interpreted considering their different lyotropic character. Conclusion: Association of siRNA with our siRNA carrier was influenced by the nature of counterions associated with chitosan. Driven by entropic phenomena including dehydration, interactions were favored by acetate counterion. Although more work would be needed to decipher the influence of the counterion of chitosan during association with siRNA, it was pointed out as a new critical attribute of chitosan to consider while formulating siRNA carrier with this polysaccharide.
\end{abstract}

Key words: siRNA, chitosan salt, siRNA carrier, counterion, lyotropic, thermodynamics

\title{
List of Abbreviation ad symbols
}

CS: generic abbreviation for chitosans used in this work

$\mathrm{CS}_{\text {Lab }}$ : chitosan prepared in our lab.

$\mathrm{CS}_{\text {Com: }}$ Commercial chitosan

CScom-mod1: Commercial chitosan modified with method 1

$\mathrm{CS}_{\mathrm{Com}}$-mod2: Commercial chitosan modified with method 2

DeltaH: normalized enthalpy

$\Delta H_{\text {fit }}$ : interaction enthalpy deduced from the fit of the curve and using equation 5

$\Delta H_{\text {graph }}$ : interaction enthalpy evaluated from graphs

$\Delta G$ : difference in free energy

$\Delta S$ : entropy of the reaction

$D_{H}$ : hydrodynamic diameter

ITC: isothermal titration calorimetry

$K_{a}$ : association constant

$K_{d}$ : dissociation constant

NP CS $S_{x x x}$ : nanoparticles prepared with the specified chitosan

NP CS xxx $-P$ : nanoparticles prepared with the specified chitosan and poloxamer 188

NP P: nanoparticles prepared with poloxamer 188

PACA: poly(alkylcyanoacrylate)

siRNA: small interfering RNA.

$-T \Delta S$ : entropic therms of the reaction 


\section{INTRODUCTION}

The discovery of siRNA at the drawn of $2000[1,2]$ has paved the way for the development of breakthrough treatments for cancers [3-9], viral infections [5,10,11], metabolic disorders [12] and neuromuscular [13] and neurodegenerative diseases [14]. In these treatments, siRNAs are designed to trigger the degradation of messenger RNAs (mRNAs) that encode for proteins which expression needs to be down regulated. mRNAs are located within the cell cytoplasm where active siRNAs need to be delivered to achieve their therapeutic potential. The poor stability of siRNAs in biological media and their incapacity to diffuse across cell membranes are tremendous hurdles for the development of siRNA-based treatments [10,15-17]. However, proof of success of siRNA-based therapeutic methods have been provided in numerous works having considered siRNA formulated nanomedicines $[6,7,10,16-18]$. Many of these nanomedicines were designed with chitosan, a polysaccharide derived from chitine which forms complexes with nucleic acids [5,9,17-33]. SiRNA associates with the nanomedicines thanks to the formation of a complex with chitosan involving electrostatic interactions between the negative charges of the phosphates of siRNA and the positive charges of the amino group of glucosamine residues found in chitosan $[26,34,35]$. The association is influenced by the molecular weight and degree of deacetylation of chitosan and by conditions in which it is performed including the $\mathrm{pH}$ of the medium and the amine to phosphate ratio $[26,29,36-38]$. The molecular weight of chitosan and its degree of deacetylation were reported to also influence the delivery performance of active siRNA in vitro and in vivo $[29,37,39-42]$

In previous works, we have reported the delivery of siRNA in intravenous treatments of two xenografted tumor models caused by junction oncogenes in mice using a chitosan-coated polymer nanoparticle designed from the poly(alkylcyanoacrylate) nanoparticle technologies $[43,44]$. The promising therapeutic perspectives shown by this nanomedicine encouraged to start its development preparing its clinical translation. The scale up of the carrier preparation is one of the first critical step which can compromise the development [45-52]. Hurdles may include methodological issues but also difficulties to find sustainable source of chemicals of the required quality. Production of clinical batches of poly(alkylcyanoacrylate) (PACA) nanoparticles was achieved during the development of Livatag ${ }^{\circledR}$, a nanomedicine considered in a phase III clinical trial for the treatment of hepatocellular carcinoma in human [53-55]. Thus, scaling-up the preparation process of the PACA nanoparticle-based siRNA carrier should not be a major difficulty for the development. In contrast, shifting the home-prepared chitosan to a commercial product was identified as a possible risk. Indeed, performances of siRNA carriers greatly depend on chitosan characteristics. While obtained from chitin, a natural compound, the quality of chitosan is subjected to variability which in turn can affect activities in biomedical applications $[26,41,56,57]$. The most cited characteristics of chitosan influencing in vitro and in vivo delivery and activity of nucleic acids including siRNA are the molecular weight and degree of deacetylation [26,36-41,58-60]. The influence of the type of salt of chitosan was studied in very few works giving mitigated results. It was considered to have a marginal effect $[10,29,40,61,62]$.

Having found a commercial chitosan which quality criteria in terms of degree of deacetylation and molecular weight that fitted those of our home-prepared chitosan, the present work was aimed to transpose the preparation of the pristine siRNA carrier made with the home-prepared chitosan with that using the chitosan of commercial source. Chitosans were characterized determining their molecular weight, degree of deacetylation, type of salt, ionization after dissolution in water. The quality of corresponding batches of nanoparticles were compared investigating their size, zeta potential, capacity to associate a siRNA and thermodynamic parameters of the interactions between the siRNA and the siRNA carrier by isothermal titration calorimetry (ITC). Additional chitosans were prepared from the commercial source changing the type of counterion towards the one present in the home-prepared chitosan. This was done to explain the 
difference in siRNA association capacity of nanoparticles prepared with the commercial chitosan compared with that of the pristine nanoparticles.

\section{Materials and Methods}

\subsection{Materials}

Isobutylcyanoacrylate (IBCA) was purchased from Orapi (Paris, France). Chitosan (20kDa, DDA 80-85\%, yellow powder) was supplied by Amicogen (Seoul, South Korea) and chitosan (medium viscosity, slightly yellow powder) by Aldrich (France). Poloxamer 188 (Pluronic ${ }^{\circledR}$ F68) a non-ionic surfactant composed of poly(oxyethylene) ${ }_{80}$-poly(oxypropylene) ${ }_{27}$-poly(oxyethylene) ${ }_{80}$ [63], was provided as a gift by BASF. The average molecular weight of poloxamer 188 is $8.400 \mathrm{~g} / \mathrm{mol}$ [64]. Cerium (IV) ammonium nitrate and nitric acid were purchased from Fluka.

The siRNA was obtained by duplex formation from the complementary single strands. (Sens/antisens strand: 5'-GCUACGGGCAGCAGAACCCD(TT)-3'; 3' -(GT)CGAUGCCCGUCGUCUUGGG-5'). The solution of $20 \mu \mathrm{M}$ of sense and antisense RNAs in annealing buffer (Eurogentec) was heated at $95^{\circ} \mathrm{C}$ for 5 min and then incubated at $37^{\circ} \mathrm{C}$ for $1 \mathrm{~h}$. The siRNA was stored at $-20^{\circ} \mathrm{C}$ until use.

\subsection{Methods}

\subsubsection{Preparation of the different chitosan}

The different chitosans used in the study were prepared according to the following procedures leading to chitosans $\mathrm{CS}_{\mathrm{Lab}}, \mathrm{CS}_{\mathrm{Com}}, \mathrm{CS}_{\mathrm{Com}} \bmod 1, \mathrm{CS}_{\mathrm{Com}}$ mod2.

Chitosan 1 ( $\left.C S_{\text {Lab }}\right)$ or home-prepared chitosan: chitosan medium viscosity at $2 \%$ in solution in acetic acid (0.1N) was hydrolyzed in conditions described by Huang et al. [36] adapted by Bertholon et al. [65] with a concentration in sodium nitrite of $11 \mathrm{~g} / \mathrm{L}$. The hydrolysis was performed at room temperature for 1 hour. The hydrolyzed chitosan was recovered by precipitation raising the $\mathrm{pH}$ at 9 with sodium hydroxide. The precipitate was recovered by centrifugation and lyophilized for $24 \mathrm{~h}$ (Alpha 2-4 LD plus, Bioblock Scientific) after freezing with liquid nitrogen.

Chitosan 2 ( CS $_{\text {com }}$ ) or commercial chitosan: was used as received from Amicogen (Seoul, South Korea)

Chitosan 3(CS com $_{\text {mod1) }}$ ) was prepared from $\mathrm{CS}_{\mathrm{com}}$ applying a method of purification based on a single dialysis (method 1). $\mathrm{CS}_{\text {com }}(2 \mathrm{~g})$ was dissolved for $30 \mathrm{~min}$ in acetic acid solution $(0.1 \mathrm{~N}, 50 \mathrm{~mL}$ ) and purified by dialysis (Spectra/Por membrane with molecular weight cut off (MWCO) of $3500 \mathrm{~g} / \mathrm{mol}$ ), twice during $1 \mathrm{~h}$ and once overnight against $1 \mathrm{~L}$ of distilled water. Lyophilization was performed for $24 \mathrm{~h}$ (Alpha 1-2 LD plus, Bioblock Scientific) after freezing with liquid nitrogen to recover $\mathrm{CS}_{\mathrm{com}}$ mod1.

Chitosan 4 ( CS $_{\text {com-mod2) }}$ was prepared from $\mathrm{CS}_{\mathrm{Com}}$ applying a method of purification by precipitation followed by a dialysis (method 2). $\mathrm{CS}_{\text {com }}(2 \mathrm{~g})$ was dissolved in acetic acid solution $(6 \%, 50 \mathrm{~mL}$ ) and stirred at room temperature for $1 \mathrm{~h}$. The $\mathrm{pH}$ was increased by adding a sodium hydroxide solution $(4 \mathrm{~N})$ until a precipitate of 
chitosan appeared ( $\mathrm{pH} 7-8)$. The precipitate was recovered by centrifugation $\left(10 \mathrm{~min}, 10^{\circ} \mathrm{C}, 4000^{*} \mathrm{~g}\right.$, rotor A-4-44, Eppendof 5804R) and subsequently washed with water (40 mL). After final centrifugation in same condition as before, it was frozen at $-80^{\circ} \mathrm{C}$ and lyophilized for $24 \mathrm{~h}$ (Alpha 1-2 LD plus, Bioblock Scientific). The obtained lyophilized powder was then dissolved again in acetic acid $(0.1 \mathrm{~N}, 40 \mathrm{~mL})$, and purified by dialysis (Spectra/Por membrane, MWCO $3500 \mathrm{~g} / \mathrm{mol}$ ), twice during $1 \mathrm{~h}$ and once overnight against $1 \mathrm{~L}$ of distilled water. Lyophilization was performed (Alpha 1-2 LD plus, Bioblock Scientific) after freezing at $-80^{\circ} \mathrm{C}$ for $24 \mathrm{~h}$ to recover $\mathrm{CS}_{\mathrm{com}}$-mod2.

\subsubsection{Characterization of chitosan}

\subsubsection{Determination of the nature of the counter ion}

Elemental analysis was used to identify inorganic counterions. The different lyophilized chitosans were analyzed by elemental analysis for their content in chloride and phosphorus (Service central d'analyse, CNRS, Solaize, France).

Acetate counter ion was identified from the presence of corresponding signal appearing around $1.8 \mathrm{ppm}$ on ${ }^{1} \mathrm{H}$ NMR spectra recorded using a spectrometer $300 \mathrm{MHz}$ (Brucker, Wissenbourg, France). Chitosan solutions were prepared at a concentration of $20 \mathrm{mg} / \mathrm{mL}$ in $\mathrm{D}_{2} \mathrm{O}$. The percentage of acetate counterion was evaluated using equation 1 by the integration on peaks at $1.8 \mathrm{ppm}$ corresponding to 3 hydrogens and the signal at around 3 ppm corresponding to the signals of $\mathrm{H} 2$ protons integrated for 2 hydrogens (Figure 1A).

Acetate counterion $(\%)=100 *\left(\frac{\frac{1}{3} H A c}{\frac{1}{2} H 2}\right) \quad$ Equation 1

\subsubsection{Determination of the molecular weight by viscosimetry}

The molecular weight of chitosan was determined by viscometry according to the procedure described by Bertholon et al. [65]. Chitosan was dissolved in a $0.1 \mathrm{M}$ acetic acid and $0.2 \mathrm{M} \mathrm{NaCl}$ solution at concentrations ranging from 1 to $2.5 \mathrm{~g} / \mathrm{L}$. The intrinsic viscosity $\left(\mathrm{cm}^{3} \cdot \mathrm{g}^{-1}\right)$ was deduced from the measurement of reduced viscosity of solutions at 5 concentrations in chitosan at $25.0^{\circ} \mathrm{C}$ using a viscometer AVS400 equipped with a Ubbelohde tube (53710/1 Schott Geräte). The molecular weight was determined using the Mark Houwink Sakurada equation using coefficients of the literature $\left(K=1.81 \times 10^{-3} \mathrm{~cm}^{3} \cdot \mathrm{g}^{-1}, a=0.93\right)[66,67]$.

\subsubsection{Determination of the degree of deacetylation of chitosan by ${ }^{1} H$ NMR spectroscopy:}

${ }^{1} \mathrm{H}$ NMR spectra were recorded using a spectrometer $300 \mathrm{MHz}$ (Brucker, Wissenbourg, France) on solutions of chitosan prepared at a concentration of $20 \mathrm{mg} / \mathrm{mL}$ in $\mathrm{D}_{2} \mathrm{O}$. The deacetylation degree $(D D A)$ was evaluated from the ${ }^{1} \mathrm{H}$ NMR spectra by the method proposed by Hirai et $a l$. [68] using equation 2.

$D D A(\%)=\left(1-\frac{\frac{1}{3} H A c}{\frac{1}{6} H 2-H 6}\right) * 100 \quad$ Equation 2

where $H A C, H 2-H 6$ referred to the proton position in the chemical structure of chitosan (Figure $1 \mathrm{~A}$ ). 

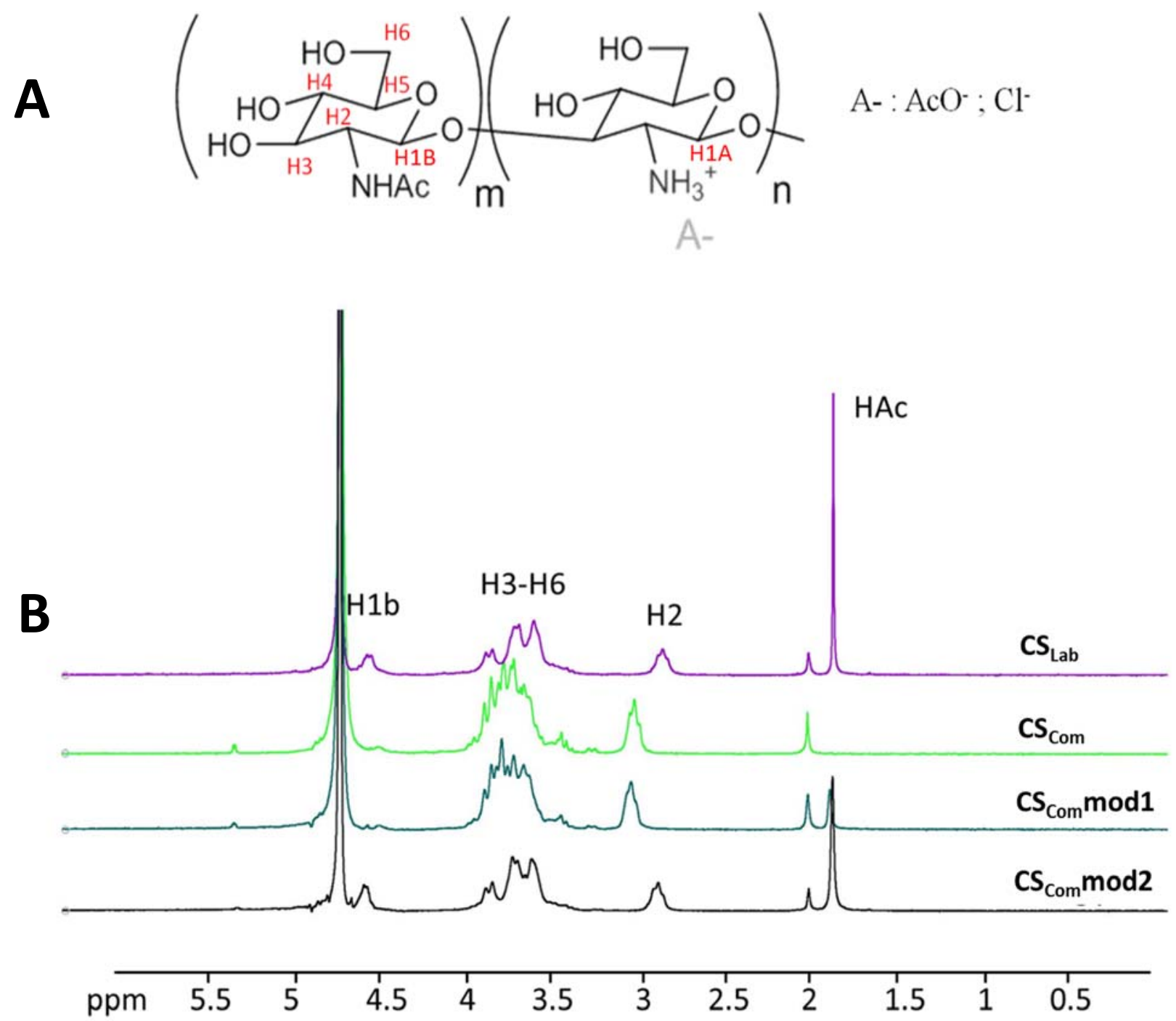

Figure 1: Chemical structure of chitosan (A) and ${ }^{1} \mathrm{H}$ NMR spectra (B) of the different chitosans in deuterium oxide solutions at a concentration of $20 \mathrm{mg} / \mathrm{mL}$. Spectra were recorded using a spectrometer $300 \mathrm{MHz}$. Signal appearing at $1.8 \mathrm{ppm}$ was attributed to the acetate counterion.

\subsubsection{Determination of the ionization of the glucosamine residue by $\mathrm{pH}$ metric}

The percentage of ionized glucosamine residues found on chitosan was evaluated by $\mathrm{pH}$ metric by measuring the $\mathrm{pH}$ of chitosan solution and performing a titration with sodium hydroxide until precipitation occurred. Chitosan was dissolved in $10 \mathrm{~mL}$ of Milli- $\mathrm{Q}^{\circ}$ water at a concentration of $2.5 \mathrm{mg} / \mathrm{mL}$. The $\mathrm{pH}$ of the solution was measured at $23^{\circ} \mathrm{C}$ (pH 210, Hanna Instruments). The solution was then titrated with a sodium hydroxide solution at $0.1 \mathrm{M}$ until a precipitation occurred. The amount of sodium hydroxide required to produce the precipitation was calculated. This provided the number of hydroxyl ions, $N$ (moles), required to neutralize the positive charged of the chitosan assuming that the precipitation of the macromolecule occurred when it became neutral in charge. Knowing the amount of chitosan dissolved in the solution and its degree of deacetylation, the fraction of ionized glucosamine residue $\left(F_{i-g / c n}\right)$ could be calculated applying equation 3 .

$F_{i-g l c n}=\frac{N}{M_{g \ln c}} \quad$ Equation 3 
With $M_{\text {glnc: }}$ : number of glucosamine residues contained in chitosan in the solution calculated from the degree of deacetylation, the amount of chitosan in the solution and the molar masses of glucosamine residues (MM: $161 \mathrm{~g} / \mathrm{mol}$ ) and of $\mathrm{N}$-acetyl glucosamine residues (MM: $203 \mathrm{~g} / \mathrm{mol}$ ).

\subsubsection{Preparation of the siRNA carrier by redox radical emulsion polymerization of isobutylcyanoacrylate.}

The siRNA carrier was prepared by redox radial emulsion polymerization according to the protocol used by De Martimprey et al. [43] and Ramon et al. [44]. Chitosan (0.068 g) and poloxamer 188 (3.5 \% w/v) were dissolved in a solution of nitric acid $0.2 \mathrm{~N}(4 \mathrm{~mL})$ at $45^{\circ} \mathrm{C}$ under vigorous magnetic stirring and nitrogen atmosphere. After $10 \mathrm{~min}$, a solution of cerium (IV) ammonium nitrate $80 \mathrm{mM} \mathrm{(1} \mathrm{mL)} \mathrm{in} \mathrm{nitric} \mathrm{acid} 0.2 \mathrm{M}$ and IBCA $(0.25 \mathrm{~mL})$ were successively added. Nitrogen bubbling was maintained for an additional $10 \mathrm{~min}$ and the polymerization was continued at constant temperature for $50 \mathrm{~min}$. At the end of the preparation, the obtained dispersion was cooled down to $+4{ }^{\circ} \mathrm{C}$ to avoid aggregation.

After cooling, the dispersion was purified by dialysis using a Spectra/Por membrane with molecular weight cut off of $100000 \mathrm{~g} / \mathrm{mol}$, three times during $1 \mathrm{~h}$ and once overnight against $0.5 \mathrm{~L}$ of Milli- $\mathrm{Q}^{\circ}$ water. This purification was efficient to remove all remaining free chitosan while it removed around $85 \%$ of the nonassociated fraction of poloxamer 188 [68].

For some experiments, nanoparticles were synthetized with only chitosan or poloxamer 188 . The same procedure was followed but corresponding media of polymerization were prepared without only poloxamer 188 or chitosan respectively.

A systematic nomenclature was used to name the different nanoparticles: NP meant nanoparticles. The letter code attached indicated whether the particles were prepared with chitosan (CS meant any type of

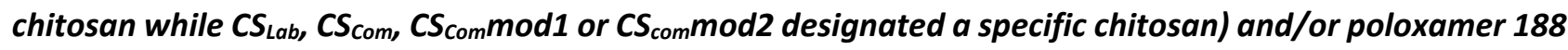
$(P)$. According to this nomenclature, the formulation corresponded to the siRNA carrier was designated by the nanoparticles named NP-CS ${ }_{L a b} P$.

\subsubsection{Characterization of the nanoparticles}

\subsubsection{Size}

The mean hydrodynamic diameter of the nanoparticles, $D_{H}$, was evaluated by dynamic light scattering (Nano ZS-90, Malvern, Orsay, France) by diluting 5 to $60 \mu \mathrm{L}$ of each nanoparticle dispersion in acetic acid $0.1 \mathrm{~N}$ (1 $\mathrm{mL}$ ). All measurements were performed at least three times on different preparations.

\subsubsection{Concentration}

The mass concentration in nanoparticles in the dispersions, $C\left(\mathrm{mg} / \mathrm{cm}^{3}\right)$, was evaluated by gravimetry after lyophilization of three aliquots $(200 \mu \mathrm{L}$ ) of the nanoparticle dispersions (Alpha 1-2 LD plus, Fisher Scientific, Illkirch, France).

The concentration of nanoparticles was also expressed in surface per volume unit, $S\left(\mathrm{~cm}^{2} / \mathrm{cm}^{3}\right)$. It was calculated from the mass concentration deduced from gravimetry measurements and the mean hydrodynamic diameter, $D_{H}$, of the nanoparticles determined by dynamic light scattering. For this calculation, 
the volumetric mass of the nanoparticles, $\rho\left(\mathrm{g} / \mathrm{cm}^{3}\right)$, was taken at 1.14 consistently with the experimental value determined for poly(isobutylcyanoacrylate) nanoparticles in a previous work [70]. The concentration of the nanoparticles in surface per volume unit calculated using equation 4

$S=\frac{6 C}{\rho D_{H}}$

Equation 4

\subsubsection{Determination of the content in chitosan of the nanoparticles by elemental analysis}

The percentage in weight of chitosan in the nanoparticles was determined by elemental analysis performed on lyophilized nanoparticles according to the methods reported previously [69]. Elemental analysis was perfomed by the Microanalysis facility of the Faculty of Pharmacy from the University of Paris Sud (Chatenay Malabry, France).

2.2.4.4 Determination of the association of siRNA with chitosan in solution and immobilized at the surface of the nanoparticles by gel electrophoresis.

siRNA was incubated at a concentration of $40 \mu \mathrm{g} / \mathrm{mL}$ with a solution of chitosan at $2 \mathrm{mg} / \mathrm{mL}$ for $15 \mathrm{~min}$ at room temperature. Presence of remaining free siRNA in an aliquot of the incubation medium $(20 \mu \mathrm{L}+9 \mu \mathrm{L}$ Glycerol) was revealed by running an electrophoresis for $1 \mathrm{~h}$ at $190 \mathrm{~V}$ in a $2 \%$ agarose gel plate containing ethidium bromide (Sigma-Aldrich). Gels were exposed to UV light in a UV light box operating at $254 \mathrm{~nm}$ to reveal the presence of siRNA thanks to the fluorescence with ethidium bromide. The same procedure was followed to investigate association of siRNA with nanoparticles using an incubation medium prepared with $0.17 \mathrm{mg} / \mathrm{mL}$ siRNA and $4.9 \mathrm{mg} / \mathrm{mL}$ nanoparticles. Consistently with the whole study, all solutions and dispersions of nanoparticles included in the incubation media were prepared with Milli- ${ }^{\circledR}{ }^{\circledR}$ water.

\subsubsection{Study of the thermodynamic characteristics of the interactions of siRNA with chitosan in solution and immobilized at the surface of nanoparticles by Isothermal titration calorimetry (ITC):}

Thermodynamic characteristics of the interactions occurring during association between siRNA and chitosan either in solution or immobilized at the surface of PIBCA nanoparticles were investigated using a VP-ITC microcalorimeter (MicroCal, Malvern Panalytical) with a sample cell volume of $1.441 \mathrm{~mL}$ at $25^{\circ} \mathrm{C}$, under constant stirring at $394 \mathrm{rpm}$. Before any measurement, the different parts of the microcalorimeter were washed with RNaseZAP (Aldrich) and rinsed several times with Milli- $Q^{\bullet}$ water to remove RNase. The solution of chitosan $(2 \mathrm{mg} / \mathrm{mL}$ ) in water or the dispersion of nanoparticles (dispersed in water and used as produced) was introduced into the titration syringe. The thermostated cell containing either Milli- $Q^{\bullet}$ water or the solution of siRNA (100 nM) in water was titrated by the water-based chitosan solution or dispersion. Each titration began with an initial injection of $5 \mu \mathrm{L}$ followed by 27 other injections of $10 \mu \mathrm{L}$ each with an interval of $400 \mathrm{~s}$ between the five first injections and $250 \mathrm{~s}$ for the following ones. Background of titration consisted on injecting the chitosan aqueous solutions or dispersion in MilliQ $^{\circ}$ water placed in the sample cell. The corresponding heat flow recorded as a function of time accounts for dilution effect.

All solutions and dispersions of nanoparticles were freshly prepared before use in ITC measurements.

Data were analyzed as follow. Raw ITC data were recorded with VP viewer 2000 ITC (version 1.4.12) software and processed with Microcal LLC, ITC software based on Origin (version 7.0) software. The dilution effect was subtracted from the titration enthalpogram. For the evaluation of the molar ratio N/P, only the deacetylated part of chitosans including glucosamine residues was considered to be available to interact with the siRNA. The concentration of chitosan was then given as a concentration of glucosamine residues expressing the 
concentration in primary amine function based on the fact that one glucosamine residue contains one primary amine function. The concentration of siRNA was expressed as a concentration of phosphate to calculate the N/P ratio corresponding to the molar ration between primary amine function of chitosan and phosphate groups of siRNA. The normalized enthalpy, DeltaH, could be calculated in $\mathrm{kJ} \cdot \mathrm{mol}^{-1}$ of primary amines and as the function of the N/P ratio. In experiments performed with solutions of poloxamer 188 and nanoparticles prepared with poloxamer 188 only, nanoparticles NP-P, concentrations in poloxamer 188 were expressed in molarity of poloxamer 188.

Based on the concentration of the two interacting species, the software used nonlinear least-squares algorithm to fit the corrected titration curve to provide with the binding constant $\left(K_{a}\right)$ and the interaction enthalpy $\left(\Delta H_{\text {fit }}\right)$. The difference in free energy $(\Delta G)$ and the entropy $(\Delta S)$ were then deducted from these values according to the Van't Hoff equation (Equation 5).

\section{$\Delta G=-R T \ln K_{a}=\Delta H_{\text {fit }}-T \Delta S \quad$ Equation 5}

The dissociation constant, $K_{d}$, was calculated from $K_{a}$ deduced from equation 4 with equation 6.

$K_{d}=1 / K_{a}$ Equation 6

A graphical evaluation of the interaction enthalpy, $\Delta H_{\text {graph }}$, was achieved from all integrated curves of titration in taking the difference between the higher and the lower enthalpy.

For experiments performed with nanoparticles, the interaction enthalpy was also expressed in $\mu \mathrm{J}$ per surface unit $\left(\mathrm{cm}^{2}\right)$ of nanoparticle available for the interaction with siRNA.

\section{Results}

\subsection{Characterization of chitosan}

Results of the characterization of chitosans were reported in table 1. The molecular weight and degree of deacetylation of $\mathrm{CS}_{\mathrm{Lab}}$ and $\mathrm{CS}_{\mathrm{Com}}$ were similar. Based on these parameters, the quality of $\mathrm{CS}_{\mathrm{Com}}$ was confirmed with the expectation. The $\mathrm{pH}$ of $\mathrm{CS}_{\mathrm{Lab}}$ and $\mathrm{CS}_{\mathrm{Com}}$ solutions obtained by simple dissolution of the polysaccharides in water were different as well as the degree of ionization of the glucosamine residues calculated from the neutralization of the charged carried by the polysaccharides. The two chitosans also differed from the nature of their salt.

Table 1: Characteristics of the chitosans

\begin{tabular}{|c|c|c|c|c|c|c|c|c|c|c|}
\hline \multirow[b]{2}{*}{ Chitosan } & \multirow[b]{2}{*}{$\begin{array}{c}\mathbf{M v}^{1} \\
(\mathrm{~g} / \mathrm{mol})\end{array}$} & \multicolumn{4}{|c|}{ Counterions $s^{2}$} & \multirow[b]{2}{*}{$\begin{array}{l}{ }^{1} \mathrm{H} \text {-NMR spectra } \\
\text { Signal } \mathrm{NH}_{3}{ }^{+}(\mathrm{ppm})\end{array}$} & \multirow[b]{2}{*}{$\begin{array}{c}\text { DDA }^{3} \\
(\%)\end{array}$} & \multirow[b]{2}{*}{$\begin{array}{c}\mathrm{pH} \text { of } \\
\text { solution }\end{array}$} & \multirow[b]{2}{*}{$\begin{array}{c}\text { Titration } \\
\text { (mMol } \mathrm{NaOH} / \mathrm{g} \\
\text { chitosan) }\end{array}$} & \multirow{2}{*}{$\begin{array}{c}\text { lonized } \\
\text { glucosamine } \\
\text { residue } \\
(\% \mathrm{~mol} / \mathrm{mol}) \\
\end{array}$} \\
\hline & & $A^{-}$ & $\begin{array}{c}\mathrm{Cl} \\
(\% \mathrm{wt} / \mathrm{wt})\end{array}$ & $\mathrm{PO}_{4}{ }^{3 \cdot}$ & $\begin{array}{l}\text { molar ratio } \\
\text { AcO/NHAc }\end{array}$ & & & & & \\
\hline$C S_{\text {bah }}$ & 20,000 & $\mathrm{AcO}-$ & 0 & $<\mathrm{DL}^{4}$ & 5 & 2.80 & 90 & 5.60 & 1.47 & 27.0 \\
\hline CScom & 15,000 & $\mathrm{Cl}^{-}$ & 12.9 & $<\mathrm{DL}^{4}$ & 0 & 2.96 & 92 & 5.29 & 3.67 & 65.6 \\
\hline CScommod1 & 31,000 & $\mathrm{AcO}-/ \mathrm{Cl}^{-}$ & 10.6 & $<\mathrm{DL}^{4}$ & 1 & 2.98 & 90 & 4.81 & 3.41 & 62.6 \\
\hline$C S_{C o m-\bmod 2}$ & 33,000 & $\mathrm{AcO} / \mathrm{Cl}^{-}$ & 0.5 & $<\mathrm{DL}^{4}$ & 6 & 2.82 & 87 & 5.35 & 1.84 & 35.3 \\
\hline
\end{tabular}

${ }^{1}$ Determined by viscometry, ${ }^{2} \mathrm{AcO}$ was revealed by ${ }^{1} \mathrm{H}-\mathrm{NMR}$ spectra (signal at $1.8 \mathrm{ppm}$ ). Mineral counter ion including $\mathrm{Cl}^{-}$and $\mathrm{PO}_{4}{ }^{3-}$ were revealed by elemental analysis, ${ }^{3}$ DDA: degree of deacetylation determined from the ${ }^{1} \mathrm{H}-\mathrm{NMR}$ spectra. ${ }^{4}<\mathrm{DL}$ : bellow the detection limit 
$\mathrm{CS}_{\text {Lab }}$ was an aetate chitosan salt as revealed by the presence of the signal at $1.8 \mathrm{ppm}$ attributed to proton of an acetate counterion on the ${ }^{1} \mathrm{H}$ NMR spectra (Figure $1 \mathrm{~B}$ spectrum $\mathrm{A}$ ). No chloride and phosphate were found in this chitosan from elemental analysis. The chitosan $\mathrm{CS}_{\mathrm{Com}}$ was a hydrochloride chitosan salt. No phosphorus was detected by elemental analysis and the ${ }^{1} \mathrm{H}$ NMR spectra did not show any signal corresponding to acetate (Figure 1B spectrum B). Because of the difference in the nature of the counterion in $\mathrm{CS}_{\text {Lab }}$ and $\mathrm{CS}_{\mathrm{Com}}$, it was decided to prepare new chitosans from $\mathrm{CS}_{\text {com }}$ exchanging the chloride counterion by the acetate counterion found in $\mathrm{CS}_{\mathrm{Lab}}$. Two procedures were applied producing $\mathrm{CS}_{\mathrm{com}} \bmod 1$ and $\mathrm{CS}_{\mathrm{Com}}$-mod2. Determinations of the counterion found in $\mathrm{CS}_{\mathrm{com}} \bmod 1$ and $\mathrm{CS}_{\mathrm{Com}}-\bmod 2$ indicated that they both contained chloride and acetate counterions (Figure 1B spectra $C$ and $D$ ) but in different proportions. The procedure used to prepare $\mathrm{CS}_{\mathrm{com}}$ mod1 did not replace much chloride and $\mathrm{CS}_{\mathrm{Com}}$ mod1 still contained a large amount of chloride counterion (10.6\%). In contrast, the content in chloride found in $\mathrm{CS}_{\mathrm{Com}}$-mod2 was low $(0.5 \%)$ while its acetate content (molar ratio $\mathrm{AcO}^{-} / \mathrm{NHAC}^{-6}$ ) appeared closed to the acetate content found in $\mathrm{CS}_{\text {Lab }}$ (molar ratio AcO/NHAc $=5$ ). The $\mathrm{pH}$ of solutions prepared with $\mathrm{CS}_{\mathrm{Com}} \bmod 1$ and $\mathrm{CS}_{\mathrm{Com}}-\bmod 2$ (4.81 and 5.31 respectively) differed from those of solutions prepared with $\mathrm{CS}_{\mathrm{Lab}}$ and $\mathrm{CS}_{\mathrm{Com}}$ (5.60 and 5.29 respectively) even though all solutions were prepared identically (Table 1 ). Regarding the ionization of the glucosamine residues, chitosan acetate salts, $\mathrm{CS}_{\text {Lab }}$ and $\mathrm{CS}_{\mathrm{Com}}$-mod2, showed the lowest ionization (27.0 and $35.3 \% \mathrm{~mol} / \mathrm{mol}$ respectively)

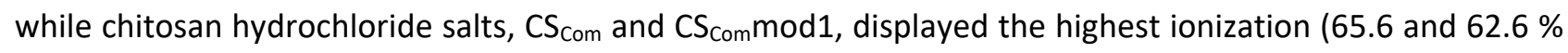
$\mathrm{mol} / \mathrm{mol}$ respectively). A linear relationship was highlighted with the square root of the chloride content (Figure 2). It seemed to us interesting to report this even if we have no explanation yet to provide.

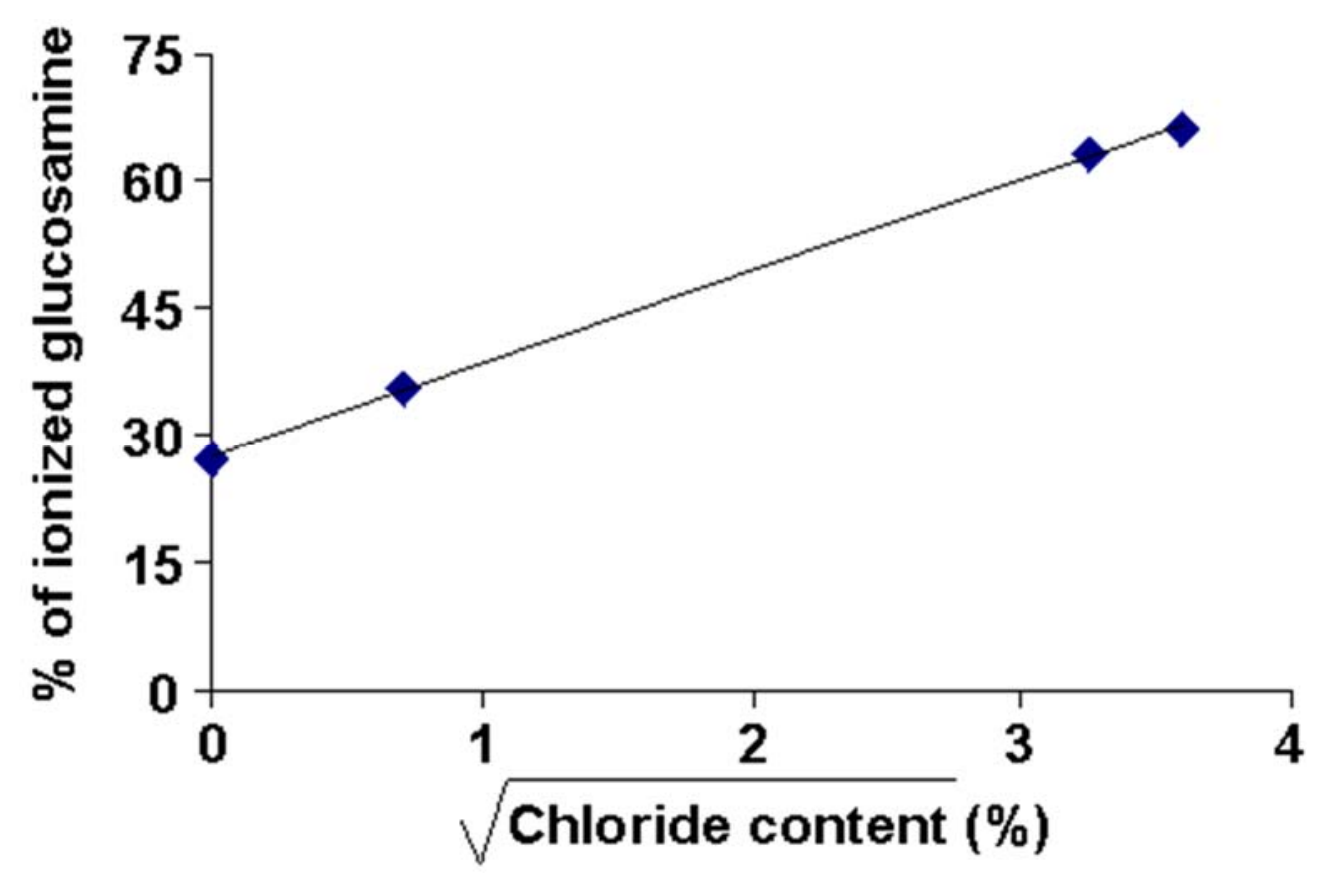

Figure 2: Percentage of ionized glucosamine residues in the different chitosan according to their content in chloride counter ion. Equation of the linear relationship is given by $y=10,829 x+27,684$ with a correlation coefficient of $R^{2}=0.9995$. 


\subsection{Quality control of nanoparticles obtained with home prepared chitosan, $\mathrm{CS}_{\mathrm{Lab}}$, and the commercially available chitosan, $\left(\mathrm{CS}_{\mathrm{Com}}\right)$.}

In the prospect of the upscale of the production of a siRNA carrier made of chitosan-coated poly(alkylcyanoacrylate) nanoparticles, the home-prepared chitosan, $\mathrm{CS}_{\mathrm{Lab}}$, was changed by a commercially available chitosan, $\mathrm{CS}_{\mathrm{Com}}$. As indicated in table 1, both chitosans showed similar quality based on their molecular weight and degree of deacetylation that are the most cited parameters influencing siRNA delivery performances of chitosan-based nanomedicines [36,37,39-41]. At first, it was verified that the quality of nanoparticles obtained at the lab scale with $\mathrm{CS}_{\text {com }}$ was comparable with quality of a batch of nanoparticles obtained with $\mathrm{CS}_{\mathrm{Lab}}$. The two batches of nanoparticles displayed very similar size, zeta potential and contents in glucosamine and poloxamer 188 (Table 2).

Table 2: Characteristics of nanoparticles and nanoparticle dispersions.

\begin{tabular}{|c|c|c|c|c|c|}
\hline Nanoparticles & $\begin{array}{c}\mathbf{D}_{\mathbf{H}} \\
(\mathrm{nm})\end{array}$ & $\begin{array}{c}\text { Zeta } \\
\text { potential } \\
(\mathrm{mV})\end{array}$ & $\begin{array}{c}\text { [Nanoparticles] } \\
(\mathrm{mg} / \mathrm{mL})\end{array}$ & $\begin{array}{c}\text { [chitosan] } \\
(\mathrm{mmol} \\
\text { glucosamine/g } \\
\text { nanoparticles })\end{array}$ & $\begin{array}{c}\text { [poloxamer 188] } \\
\text { (mmol/g } \\
\text { nanoparticles })\end{array}$ \\
\hline$N P-C S_{\text {Lab }}$ & $208 \pm 25$ & $+40 \pm 1$ & 12 & 1.25 & - \\
\hline$N P-C S_{\text {Com }}$ & $381 \pm 65$ & $+37 \pm 3$ & 12 & 1.29 & 0.032 \\
\hline$N P-P$ & $60 \pm 7$ & $-18 \pm 2$ & 16 & - & 0.018 \\
\hline$N P-C S_{\text {Lab }} P$ & $42 \pm 8$ & $+11 \pm 2$ & 49 & 0.27 & 0.018 \\
\hline$N P-C S_{\text {com }} P$ & $53 \pm 12$ & $+11 \pm 1$ & 36 & 0.28 & 0.018 \\
\hline$N P-C S_{\text {commod1P }}$ & $50 \pm 12$ & $\mathrm{nd}$ & 40 & 0.27 & 0.018 \\
\hline$N P-C S_{\text {commod2P }}$ & $55 \pm 15$ & $+13 \pm 3$ & 41 & 0.26 & \\
\hline
\end{tabular}

The figure 3 reports results of the evaluation of the association of the siRNA assessed by gel electrophoresis.The intensity of the fluorescent bands appearing on the gels informed about the amount of remaining free siRNA in samples. A reference sample given the intensity of the band in case no association occurred was provided from the analysis of a solution of siRNA at the same concentration than that used in samples incubated with nanoparticles or chitosan (see figure 3, rows siRNA). Intensities of bands shown by samples containing nanoparticles or chitosan in solutions were much lower than that of the free siRNA reference indicated that at least part of the siRNA associated with the tested material. The results indicated a good association of the siRNA with the carrier or the chitosan. The low intensity of the band corresponded to free siRNA remaining in the siRNA carrier containing sample agreed with previous quantitative determinations showing that our siRNA carrier could associated around $95 \%$ of siRNA [43,44]. A lower intensity of the bands could be highlighted considering the siRNA carrier prepared with $\mathrm{CS}_{\text {Lab }}$ compared with that prepared with $\mathrm{CS}_{\mathrm{Com}}$. No fluorescent band appeared on the gel for the sample prepared with a solution of $\mathrm{CS}_{\mathrm{Lab}}$ indicating that this chitosan associated the total amount of siRNA while provided under the form of a solution. Results of the analysis of the remaining free fraction of siRNA in samples by gel electrophoresis revealed that the quality of the nanoparticles prepared with $\mathrm{CS}_{\mathrm{Lab}}$ and $\mathrm{CS}_{\mathrm{Com}}$ differed regarding their capacity to associate siRNA. In solution, chitosan $\mathrm{CS}_{\text {com }}$ associated clearly less siRNA than $\mathrm{CS}_{\text {Lab }}$ while association experiments were performed in identical conditions. 

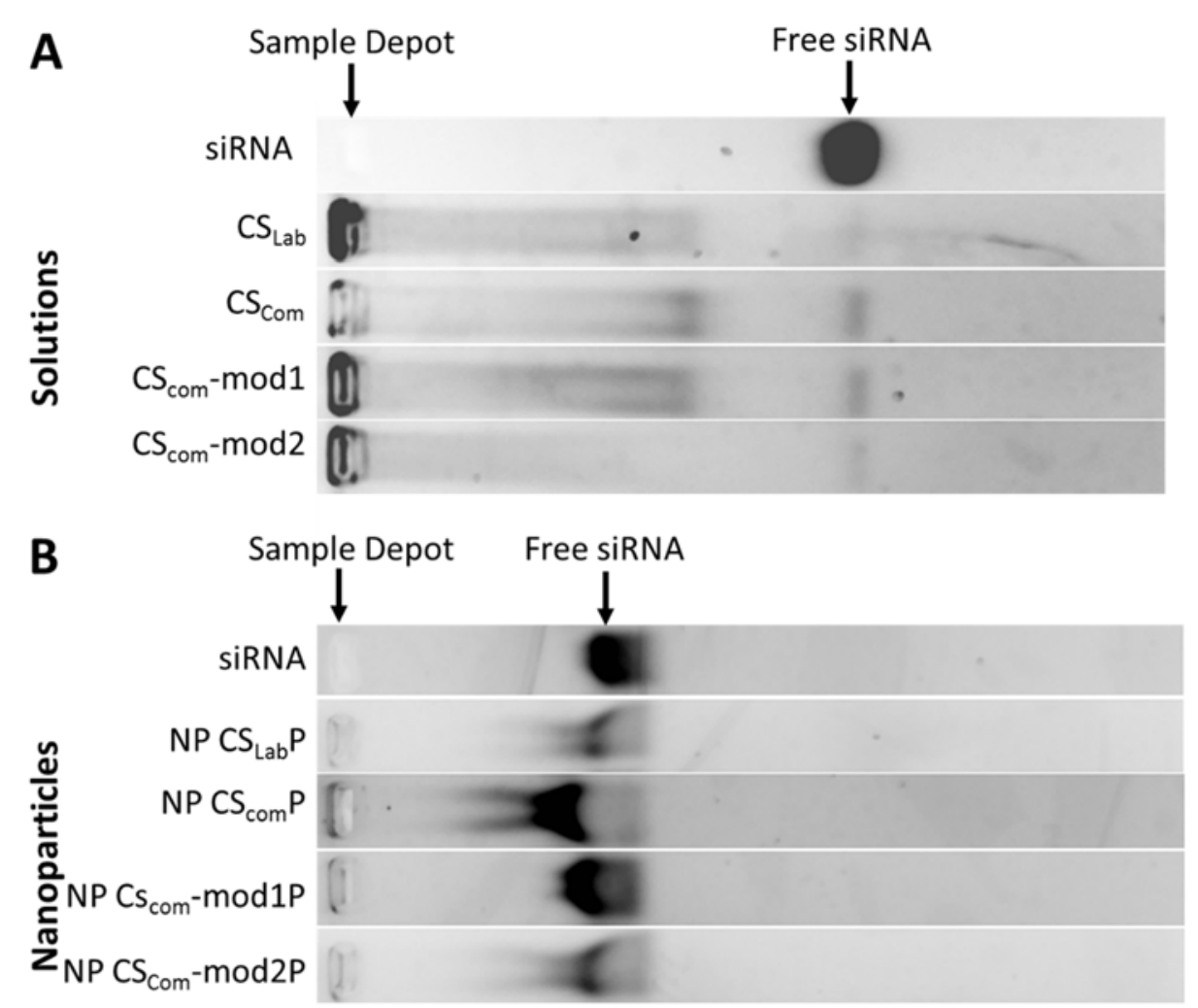

Figure 3: Association of the siRNA with chitosan in solution (A) and immobilized the surface of the siRNA carrier (B) as evaluated by gel electrophoresis. $\mathrm{CS}_{\mathrm{Lab}}, \mathrm{CS}_{\mathrm{Com}}, \mathrm{CS}_{\mathrm{Com}}$ mod1, $\mathrm{CS}_{\mathrm{Com}}$ mod2 referred to the type of chitosan used to prepare the solutions or the siRNA carrier. Presence of siRNA in the gel was revealed by fluorescence using ethidium bromide. At the migration position of the siRNA, the darker the migration bands appeared, the highest was the amount of free siRNA in samples containing either chitosan in solution or siRNA carriers. The lighter was this band, the higher the amount of siRNA was retained in the complex with chitosan in the solutions or chitosan immobilized at the surface of the siRNA carrier

\subsection{Influence of the type of chitosan salt on siRNA association}

The figure 3 showed that the association of siRNA with samples prepared with $\mathrm{CS}_{\text {com-mod}} 2$ appeared similar to that observed with samples prepared with $\mathrm{CS}_{\text {Lab }}$ while the association of siRNA with samples prepared with $\mathrm{CS}_{\mathrm{Com}}$ and $\mathrm{CS}_{\mathrm{Com}}$ mod1 were comparable. Samples prepared with chitosan acetate salt (solutions of $\mathrm{CS}_{\mathrm{Lab}}$ and $\mathrm{CS}_{\mathrm{Com}}-\bmod 2$ and nanoparticles NP- $\mathrm{CS}_{\mathrm{Lab}} \mathrm{P}$ and NP- $\mathrm{CS}_{\mathrm{Com}}-\bmod 2 \mathrm{P}$ ) associated slightly better siRNA than those prepared with chitosan hydrochloride salts (solutions of $\mathrm{CS}_{\mathrm{com}}$ and $\mathrm{CS}_{\mathrm{com}} \bmod 1$ and nanoparticles NP- $\mathrm{CS}_{\mathrm{com}} \mathrm{P}$ and NP- CS commod1P).

\subsection{Thermodynamic characteristics of the interactions between siRNA and chitosan}

Thermodynamic characteristics of the interactions between siRNA and chitosan were investigated by ITC. In the present study, chitosan occurred as free solubilized polymer chains in solutions, $\mathrm{CS}_{\text {Lab }}$ to $\mathrm{CS}_{\mathrm{Com}}$-mod2, or as a polymer chain immobilized on the surface of nanoparticles. The nanoparticle surface of siRNA carriers, i.e. nanoparticles NP- $\mathrm{CS}_{\mathrm{Lab}} \mathrm{P}, \mathrm{NP}-\mathrm{CS}_{\mathrm{Com}} \mathrm{P}, \mathrm{NP}-\mathrm{CS}_{\mathrm{Com}} \bmod 1 \mathrm{P}$ and NP- $\mathrm{CS}_{\mathrm{Com}}$-mod2P, included one type of chitosan and poloxamer 188 [69]. Some experiments were performed with simpler nanoparticle formulations

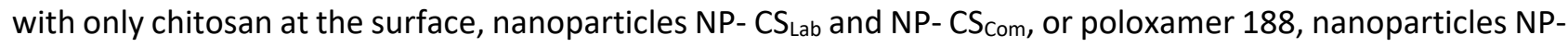
P. A solution of poloxamer 188 was considered as well in these experiments. 
The figure 4 presents representative graphs of the heat rate monitored as a function of time during titration experiments of different samples prepared with chitosan $\mathrm{CS}_{\mathrm{Lab}}$ and poloxamer 188 . Same trends were observed considering corresponding samples prepared with $\mathrm{CS}_{\text {com }}$. Sharp positive peaks recorded during titration performed with solutions of chitosan (see for instance Figure $4 \mathrm{~A}$ ) and dispersions of nanoparticles having only chitosan on the surface (nanoparticles NP- $\mathrm{CS}_{\text {Lab }}$ and NP- $\mathrm{CS}_{\text {com }}$ ) (see for instance Figure $4 \mathrm{C}$ ) indicated endothermic interactions which can result from the occurrence of dehydration phenomena. Negative peaks monitoring exothermic events were recorded during titrations involving samples containing only poloxamer 188 . The low variation of amplitude from the beginning and to the end of the titration suggested that interactions having generated these signals were negligible (Figure 4B,D). Raw signals obtained from titrations performed with the siRNA carrier (Figure $4 \mathrm{E}$ ) monitored the occurrence of an endothermic event (positive peaks) followed by an exothermic event (negative peaks). The amplitude of the exothermic signal was $5 \mu$ Watt which was twice higher than the amplitude monitored studying interactions of siRNA with nanoparticles NP-P. This suggested that siRNA interactions with nanoparticles prepared with chitosan and poloxamer 188 involved a distinct phenomenon. The exothermic signals acknowledged the occurrence of specific interactions, i.e. formation of hydrogen or electrostatic bonds, Van der Waals interactions.

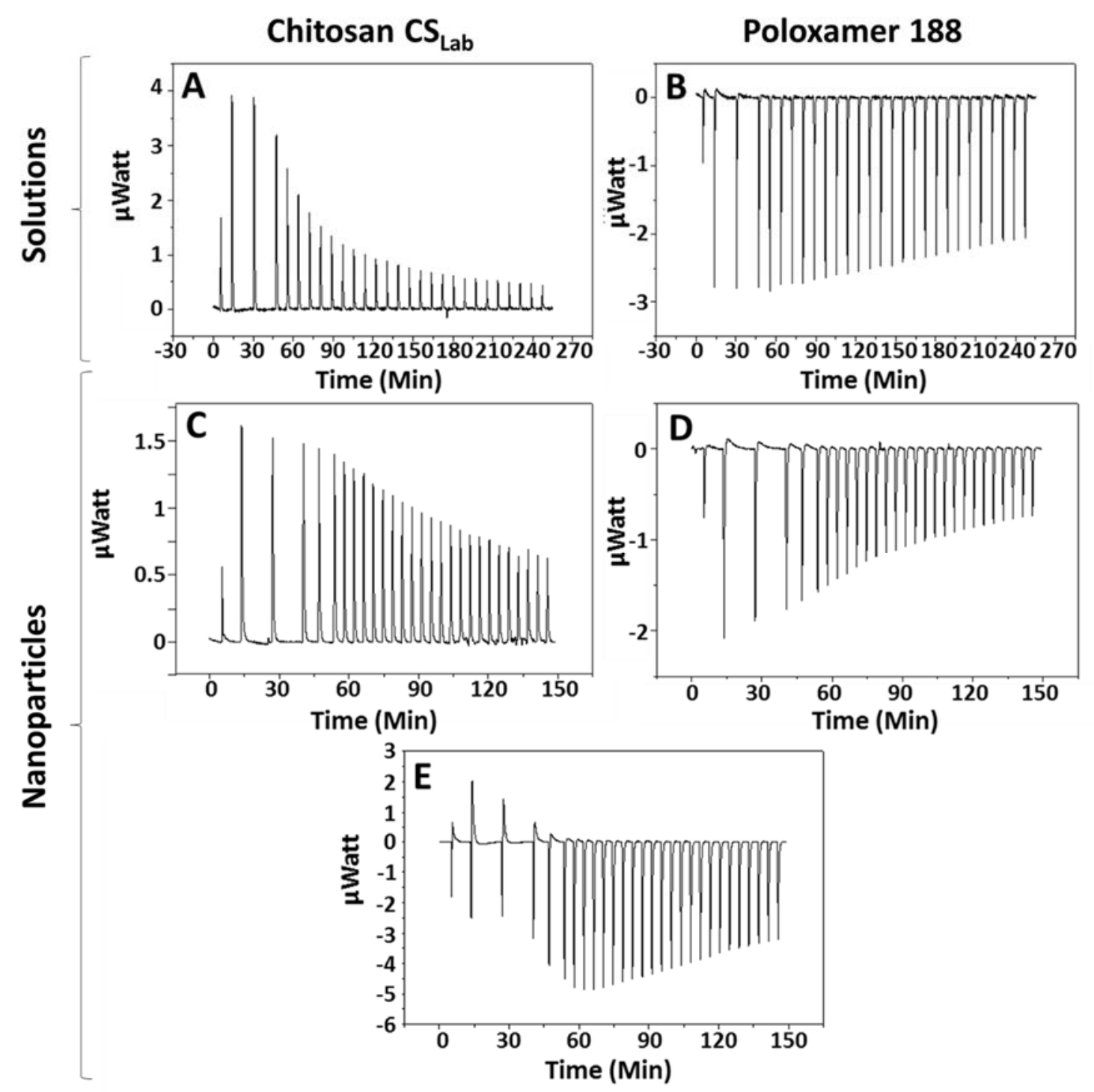

Figure 4: Example of raw ITC signal recovered from the titration of siRNA with $\mathrm{CS}_{\mathrm{Lab}}$ in solution (A); poloxamer 188 in solution (B); NP- $C_{\text {Lab }}(C)$; NP-P nanoparticles (D) and NP- CS $_{\text {Lab }}$ P nanoparticles (E). 
Graphs of the figure 5 present the normalized experimental interaction heat change, DeltaH, measured by ITC for the different experiments. The variation of DeltaH monitored for interactions occurring between siRNA and poloxamer 188 solutions or NP-P nanoparticles was near zero confirming that interactions detectable by ITC were negligible but the existence of possible athermal interactions cannot be excluded according to Ma et al. [71] (Figure 5Aa, Ba). Experiments performed with chitosan solutions and nanoparticles coated with both chitosan and poloxamer (NP- $\mathrm{CS}_{\mathrm{Lab}} \mathrm{P}, \mathrm{NP}-\mathrm{CS}_{\text {mod }} \mathrm{P}, \mathrm{NP}-$ $\mathrm{CS}_{\text {com-mod1P, NP- }} \mathrm{CS}_{\mathrm{com}}$-mod2P) provided curves that followed a biphasic model (Figure 5Ab, Ac, Bb, $\mathrm{BC}$ ). The endothermic part of the curves (second part of the curves) could be fitted with the one binding site model providing the interaction enthalpy, $\Delta H_{\text {fit }}\left(\mathrm{J} \cdot \mathrm{mol}^{-1}\right)$, and the dissociation constant, $K_{d}(\mathrm{M})$. The results were included in table 3 and figure 6.

\section{Solutions}

A (Delta $\mathrm{H}$ in $\mathrm{KJ} / \mathrm{mol}$ )
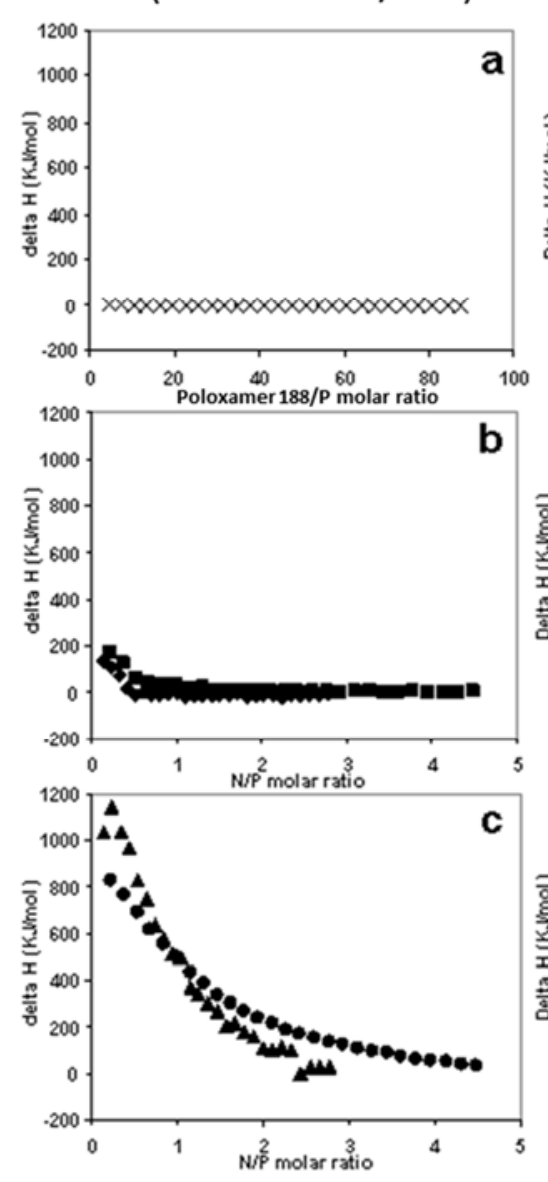

Nanoparticles

B (Delta $\mathrm{H}$ in KJ/mol)
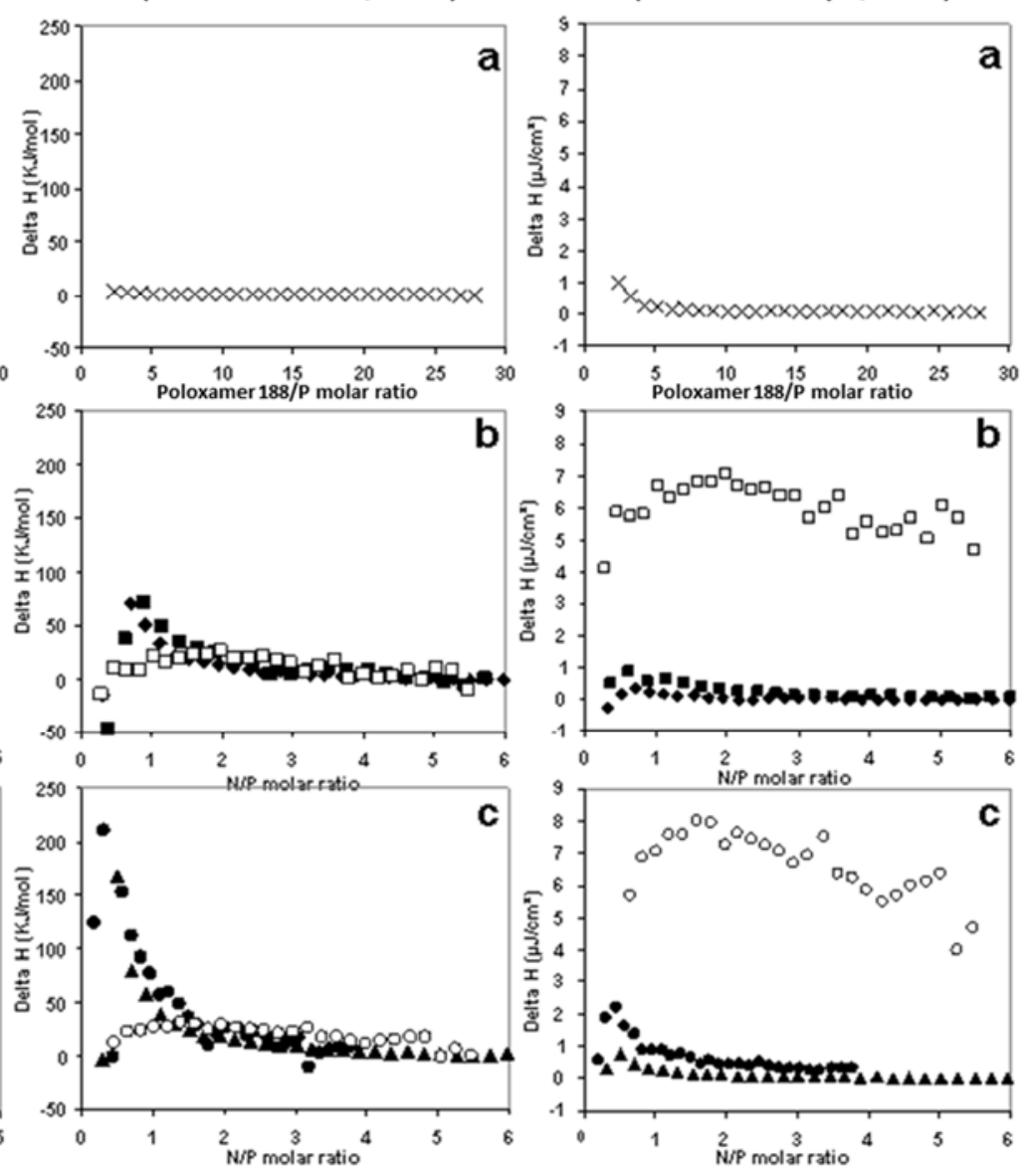

C (Delta $\mathrm{H}$ in $\mu \mathrm{J} / \mathrm{cm}^{2}$ )
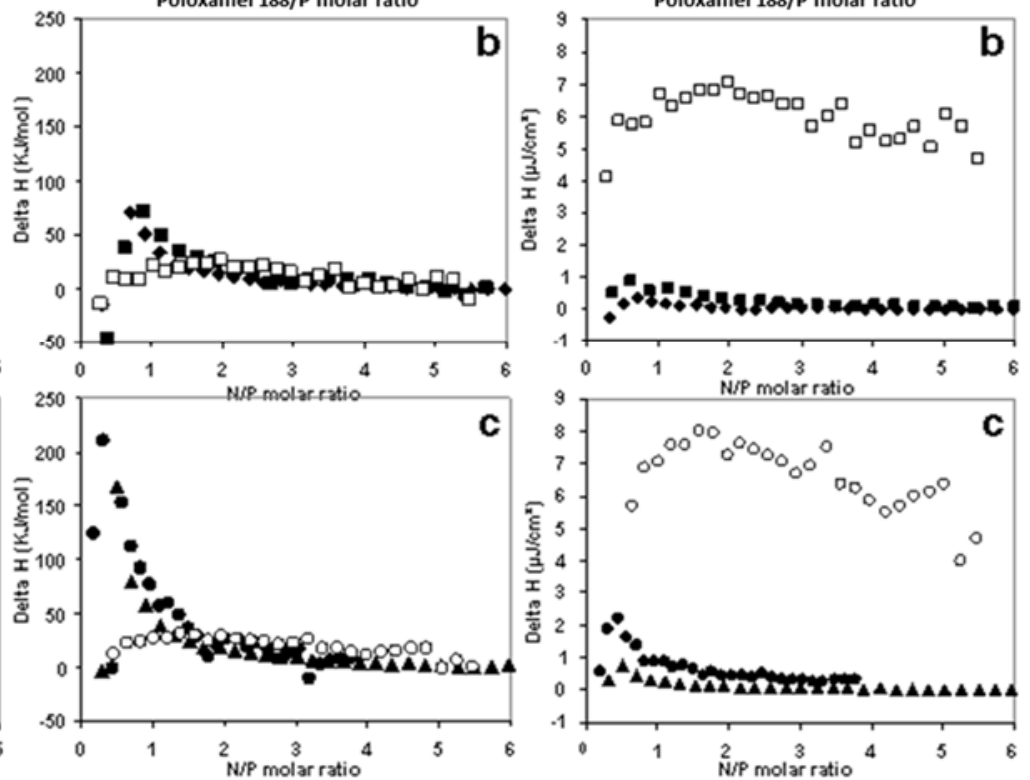

Figure 5: Normalized heat change per injection of the interaction occurring between siRNA and chitosan in solution (column $A$ ) or chitosan immobilized at the surface of nanoparticles with or without poloxamer 188 (columns $B$ in $\mathrm{KJ} / \mathrm{mol}$ and $\mathrm{C}$ in $\mu \mathrm{J} / \mathrm{cm}^{2}$ ). (Aa) solution of poloxamer 188, (Ab) solutions of $\mathrm{CS}_{\mathrm{Lab}}(\boldsymbol{\square})$ and $\mathrm{CS}_{\mathrm{Com}}-\bmod 2(\boldsymbol{\nabla})$, (Ac) solutions of $\mathrm{CS}_{\mathrm{Com}}(\bullet)$ and $\mathrm{CS}_{\mathrm{Com}} \bmod 1(\mathbf{\Delta})$; (Ba and $\left.\mathrm{Ca}\right)$

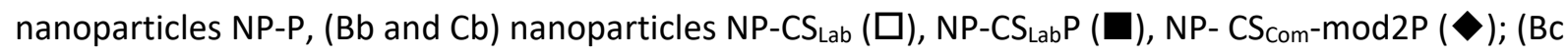
and $\mathrm{CC}$ ) nanoparticles NP-CS com $(\mathbf{O})$, NP- $\mathrm{CS}_{\mathrm{com}} \mathrm{P}(\bullet), \mathrm{NP}-\mathrm{CS}_{\mathrm{com}} \bmod 1 \mathrm{P}(\mathbf{\Delta})$; $(\mathrm{Aa}, \mathrm{Ba}, \mathrm{Ca})$ poloxamer 188/P corresponded to the molar ratio between poloxamer 188 and phosphate groups of the siRNA; $(\mathrm{Ab}, \mathrm{Bb}, \mathrm{Cb}) \mathrm{N} / \mathrm{P}$ corresponded to the molar fraction between the amine functions of glucosamine residues of chitosan and phosphate groups of the siRNA. 
Table 3: Thermodynamic characteristics of interactions between siRNA and chitosan occurring as a solution (A) or immobilized on the surface of nanoparticles (B)

\begin{tabular}{|c|c|c|c|c|}
\hline A & Counterions $^{1}$ & $\begin{array}{l}\mathrm{K}_{\mathrm{a}}^{*} \\
\left(\mathrm{M}^{-1}\right)\end{array}$ & $\begin{array}{l}\mathrm{K}_{\mathrm{d}}^{* *} \\
(\mathrm{M})\end{array}$ & $\begin{array}{r}\Delta \mathbf{H}_{\text {graph }} \\
\left(\mathrm{kJ} \cdot \mathrm{mol}^{-1}\right)\end{array}$ \\
\hline$C S_{L a b}$ & $\mathrm{AcO}^{-}$ & $1.4 \pm 0.310^{6}$ & $0.8 \pm 0.210^{-6}$ & 170 \\
\hline$C S_{\text {Com }}$ & $\mathrm{Cl}^{-}$ & $1.1 \pm 0.110^{6}$ & $0.9 \pm 0.110^{-6}$ & 830 \\
\hline$C S_{\text {com } \bmod 1}$ & $\mathrm{Cl}^{-} / \mathrm{AcO}^{-}$ & $3.6 \pm 0.710^{6}$ & $0.28 \pm 0.0510^{-6}$ & 1100 \\
\hline$C S_{\text {commod2 }}$ & $\mathrm{AcO}^{-} / \mathrm{Cl}^{-}$ & $1.6 \pm 0.210^{6}$ & $0.59 \pm 0.0410^{-6}$ & 230 \\
\hline poloxamer 188 & - & - & - & 0 \\
\hline
\end{tabular}

\begin{tabular}{|c|c|c|c|c|}
\hline $\begin{array}{l}\text { B } \\
\text { Nanoparticles }\end{array}$ & $\begin{array}{l}\mathrm{K}_{\mathrm{a}}^{*} \\
\left(\mathrm{M}^{-1}\right)\end{array}$ & $\begin{array}{l}\mathrm{K}_{\mathrm{d}} * * \\
(\mathrm{M})\end{array}$ & $\begin{array}{c}\Delta \mathbf{H}_{\text {graph }} \\
\left(\mathrm{kJ} \mathrm{mol}^{-1}\right)\end{array}$ & $\begin{array}{c}\Delta \mathbf{H}_{\text {graph }}^{\prime} \\
\left(\mu \mathrm{J} \cdot \mathrm{cm}^{-2}\right)\end{array}$ \\
\hline$N P-C S_{L a b}$ & nd & nd & 21 & 4.3 \\
\hline$N P-C S_{C o m}$ & nd & nd & 31 & 12.2 \\
\hline$N P-P$ & nd & nd & 4 & 1.0 \\
\hline$N P-C S_{L a b} P$ & $0.6 \pm 0.210^{6}$ & $1.7 \pm 0.410^{-6}$ & 72 & 0.3 \\
\hline$N P-C S_{\text {Com }} P$ & $0.7 \pm 0.110^{6}$ & $1.5 \pm 0.310^{-6}$ & 280 & 0.9 \\
\hline$N P-C S_{\text {commod1P }}$ & $0.60 \pm 0.0510^{6}$ & $1.6 \pm 0.110^{-6}$ & 170 & 0.6 \\
\hline$N P-C S_{c o m} \bmod 2 P$ & $0.64 \pm 0.0510^{6}$ & $1.6 \pm 0.110^{-6}$ & 71 & 0.8 \\
\hline
\end{tabular}

${ }^{1}$ from table $1,{ }^{*} K_{a}$ Binding constants were deduced from the fit of the endothermic part (second part) of the curves giving the enthalpy of interaction as a function of the molar ratios of the reactants using the ITC one binding site model. ${ }^{* *} K_{d}$ dissociation constant calculated from the inverse of $K_{a}$. (nd curves could not be fitted)

In general, the interaction enthalpy, $\Delta H$, contribution of the free energy of interaction, were the highest for samples prepared with chitosan only, i.e. chitosan solutions and NP-CS Lab to NP- CS $_{\text {Com-mod2 }}$ nanoparticles. It varied from 100 to more than $1000 \mathrm{~kJ} . \mathrm{mol}^{-1}$. Interaction enthalpies were much higher considering samples containing also poloxamer 188, i.e. siRNA carriers including NP- $\mathrm{CS}_{\text {Lab }}$ P to NP-

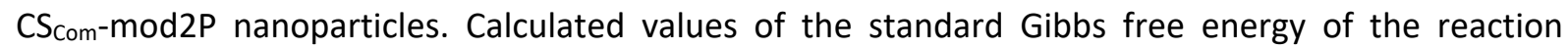
deduced from the Van't Hoff equation (Equation 5) were negative, indicating spontaneous interactions between siRNA and components of the tested samples. The positive value of the entropy acknowledged entropic driven phenomena that can be attributed to dehydration and chain rearrangement phenomena. Values of the entropic term, $T \Delta S$, and of the enthalpy term, $\Delta H_{f i t}$, of the reaction appeared similar in absolute values, indicating that it involved the formation of electrostatic bonds and acknowledged the occurrence of a dehydration process as well. The normalized interaction heat change per injection, DeltaH, monitored during titration was also expressed in $\mu \mathrm{J}$ per surface unit of nanoparticle available for the interaction with siRNA (figure $5 \mathrm{Ca}, \mathrm{Cb}, \mathrm{Cc}$ ) to better highlight the influence of the nanoparticle surface on their interaction. The interaction enthalpy, $\Delta H_{\text {graph }}^{\prime}$, was evaluated from the difference between the higher and lower DeltaH recorded during titration. Lowest values were obtained considering the nanoparticles coated with both chitosan and poloxamer (NP$\left.\mathrm{CS}_{\text {Lab }} \mathrm{P}, \mathrm{NP}-\mathrm{CS}_{\bmod } \mathrm{P}, \mathrm{NP}-\mathrm{CS}_{\mathrm{Com}}-\bmod 1 \mathrm{P}, \mathrm{NP}-\mathrm{CS}_{\mathrm{Com}}-\bmod 2 \mathrm{P}\right)$ consistently with the other results. 


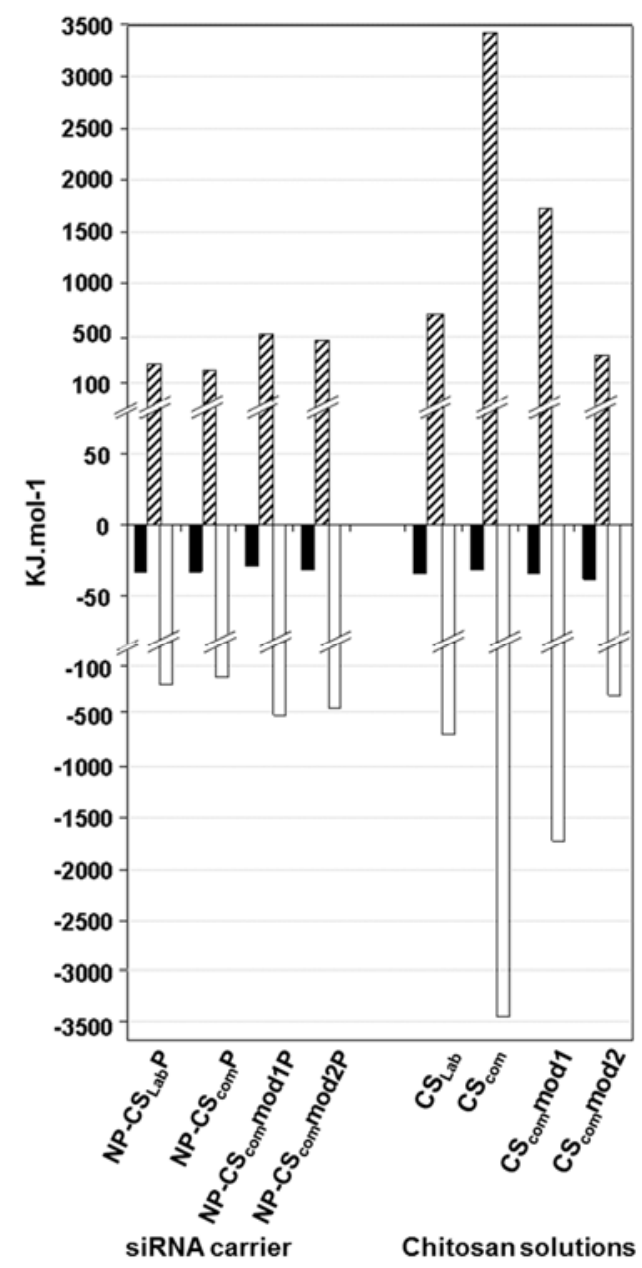

Figure 6: Comparison of thermodynamic characteristics of interactions between siRNA and chitosan either in solution or on nanoparticles (NP-CSP). Interaction enthalpy $\left(\Delta H_{f i t}\right)$ was given by the one binding site model fit of the integrated data shown on figure 5 (Hached bars). Entropy term (-TAS) (empty bars) and the standard Gibbs free energy $(\Delta G)$ (full bars) were calculated from $\Delta H_{\text {fit }}$ and of the binding constant given by the fit by applying the Van't Hoff equation (Equation 5).

Binding constants could be determined from isotherms monitoring interactions of siRNA with chitosan in solutions and with nanoparticles NP- $\mathrm{CS}_{\mathrm{Lab}} \mathrm{P}$ to NP- $\mathrm{CS}_{\mathrm{Com}}-\bmod 2 \mathrm{P}$. Dissociation constants calculated from the binding constants ranged between 1.02 to $7.6910^{-6} \mathrm{M}$. They were of the same order of magnitude for the different samples indicating that the nature of interactions occurring with siRNA was the same whether chitosan was in solution or immobilized at the surface of nanoparticles together with poloxamer 188 (Table 3).

\section{Discussion}

Scaling up the preparation of a nanomedicine can be a bottleneck to its clinical translation [45-52]. Beside potential methodological difficulties to reproduce the nanomedicine with similar quality and efficiency than that produced at the lab scale, suitable amount of chemicals responding to the required quality criteria must be available. To achieve the development of a siRNA carrier based on the poly(alkylcyanoacrylate) nanoparticle technology, a commercial source of chitosan was needed to 
replace the home-tediously prepared batches of chitosans used to carry on our research projects $[43,44]$. The new source of chitosan was selected based on structural parameters known to influence the formation of complex with siRNA and interfering with the siRNA activity obtained in vitro and in vivo. Consistently, quality criteria included a similarity of the degree of deacetylation and molecular weight as they were the most cited structural parameters of chitosan influencing performances of nucleic acid chitosan-based carriers $[26,30,35,37,38,40,41,60]$. Nanoparticles designed as siRNA carrier produced with the home-prepared chitosan, NP-CS $\mathrm{Lab}_{\mathrm{La}} \mathrm{P}$, and chitosan of the commercial source, NP$\mathrm{CS}_{\mathrm{Com}} \mathrm{P}$, displayed very similar quality based on size and zeta potential criteria. However, further investigations of the qualities of the siRNA carrier obtained with $\mathrm{CS}_{\text {com }}$ revealed a lower capacity to associate siRNA accompanied by a modification of thermodynamic parameters of interactions with siRNA highlighted by ITC.

Based on the literature, association of siRNA with the carrier was assumed to take place thanks to electrostatic interactions with chitosan $[26,34,35]$ whereas chitosan was stranded at the nanoparticle surface together with poly(ethylene glycol) (PEG) chains of poloxamer 188 [69]. The similarity of binding constants found considering association of siRNA with chitosan in solution or with siRNA carriers acknowledged interactions of similar nature attributed to interactions of the siRNA with chitosan found in both samples. Consistently, ITC experiments also confirmed that poloxamer 188, either on solution or alone at the surface of the nanoparticles NP-P, did not interact directly with the siRNA during association with the siRNA carrier as barely no interaction involving thermal exchange detectable by ITC were evidenced (Figure $5 \mathrm{Aa}, \mathrm{Ba}$ ). The predominant role of chitosan while associating siRNA with the carrier was observed independently of the source of chitosan used to prepare the siRNA carrier. However, the difference in siRNA association capacity and thermodynamic conditions of the interactions observed between samples prepared with $\mathrm{CS}_{\mathrm{Lab}}$ and $\mathrm{CS}_{\mathrm{Com}}$ could not be explained by a difference in degree of deacetylation and molecular weight of chitosans as both were very similar based on these characteristics. Although not considered as an important parameter influencing siRNA association with chitosan $[10,26,29,40,61]$, we have postulated that the difference in the type of salt revealed from our analysis of $\mathrm{CS}_{\mathrm{Lab}}$ and $\mathrm{CS}_{\text {com }}$ could explain the difference of siRNA association highlighted by gel electrophoresis (Figure 3). This hypothesis was supported from results of experiments performed with $\mathrm{CS}_{\mathrm{Com}} \bmod 1$ and $\mathrm{CS}_{\mathrm{Com}}$-mod2 that were prepared from $\mathrm{CS}_{\mathrm{Com}}$ with the aim to exchange the chloride counterion by acetate, the counterion found in $\mathrm{CS}_{\text {Lab. }}$. Samples prepared with $\mathrm{CS}_{\mathrm{Com}}$-mod2, which contained the lower amount of chloride salt and the highest amount of acetate salt, associated the siRNA like those prepared with $\mathrm{CS}_{\text {Lab. }}$. The restoration of the capacity to better associate siRNA taking a chitosan acetate salt, $\mathrm{CS}_{\mathrm{Com}}$ - $\bmod 2$, prepared from a chitosan hydrochloride salt, $\mathrm{CS}_{\mathrm{Com}}$, was never reported before but supported our hypothesis. Investigations of thermodynamic parameters of interactions between siRNA and various samples prepared with different chitosans by ITC have provided more proofs on the influence of the type of salt of chitosan while associating siRNA with a chitosan-based carrier. In this set of experiments, thermodynamic parameters of the interactions of siRNA with samples prepared with $\mathrm{CS}_{\text {Lab }}$ and $\mathrm{CS}_{\mathrm{Com}}$ differed (see figure 6). In contrast, consistent results were obtained considering samples prepared with either the two chitosan acetate salts, $\mathrm{CS}_{\text {Lab }}$ and $\mathrm{CS}_{\mathrm{Com}}-\bmod 2$, or the two chitosan chloride salts, $\mathrm{CS}_{\mathrm{Com}}$ and $\mathrm{CS}_{\mathrm{Com}}$ mod1. The fact that thermodynamic parameters of interactions of siRNA with samples prepared with $\mathrm{CS}_{\mathrm{com}}$ were changed into those found with samples prepared with $\mathrm{CS}_{\text {Lab }}$ exchanging the chloride counterion by acetate, i.e. preparing samples with $\mathrm{CS}_{\mathrm{Com}}$-mod2, demonstrated a clear influence of the nature of chitosan salt on interactions between siRNA and chitosan independently of its presentation, i.e. solution or 
immobilized at the surface of nanoparticles. According to our results, the nature of the salt of chitosan influenced slightly the capacity of chitosan to associate siRNA with chitosan-based carriers, but it influenced the thermodynamic characteristics of the interactions hence their mechanisms. This may have consequences on stability of complexes and release of the siRNA hence activity of the nanocarriers and will need to be considered in future work. Thus, the nature of the salt of chitosan should be considered as another key attribute of chitosan to achieve siRNA-carrier quality while the only structural parameters including the degree of deacetylation and molecular weight were taken into account so far $[26,30,35,37,38,40,41,62]$.

The aim of the present work was not to elucidate the role of the nature of salt of chitosan on the formation of complexes with siRNA but results from our ITC experiments provided some clues. Interactions between siRNA and chitosan or nanoparticles with chitosan on their surface occurred spontaneously being driven by entropic phenomena. Both electrostatic interactions and nonelectrostatic interactions were involved during complex formation, the latter being attributed to dehydration phenomena and molecular rearrangements. Dehydration phenomena can be affected by the lyotropic character of ions due to their salting-out and salting-in effect produced on macromolecules [72-74]. In the Hofmeister series which gives a classification of anions according to their lyotropic character, acetate anions are more hydrated than chloride anions producing the strongest salting-out effect on macromolecules [72-78]. From our samples, it can be postulated that the lyotropic character of counterions of chitosan may influence the dehydration of chitosans chain influencing thermodynamic conditions of their interactions with siRNA. According to this hypothesis, the salting-out effect produced on chitosan chains by acetate counterions would be stronger than that produced by the chloride counterions hence reducing the entropy term of interaction, $T \Delta S$, assuming that the chitosan chain interacting with siRNA would already be more dehydrated. This was consistent with what was observed considering samples containing chitosan in solutions where the monitored entropy of interactions was reduced with solutions of chitosan acetate, $\mathrm{CS}_{\mathrm{Lab}}$ and $\mathrm{CS}_{\mathrm{Com}}$-mod2, compared with corresponding samples prepared with chitosan hydrochloride $\left(\mathrm{CS}_{\mathrm{Com}}\right.$ and $\left.\mathrm{CS}_{\mathrm{com}} \mathrm{mod} 1\right)$ (figure 6). At the surface of our siRNA carrier, the salting-out effect produced by counterions on the chitosan chains may indirectly be reinforced by surrounding PEG chains of poloxamer 188 . Indeed, PEG can behave like salting-out agent on biological macromolecules [79]. It was also reported to enhance the salting-out effect caused by anions on another polycations used to formulate delivery systems for nucleic acids by a crowding effect $[73,80,81]$. Although our results suggested that poloxamer 188 did not interact directly with siRNA, its PEG chains may indirectly interfere on the dehydration of the chitosan chains stranded on the surface of the siRNA carrier according to salting-out mechanisms. This could explain the entropic gain observed comparing entropic terms of interactions in samples containing chitosan solutions of $\mathrm{CS}_{\mathrm{Com}}\left(-3430 \mathrm{~kJ} \mathrm{~mol}^{-1}\right)$ and $\mathrm{CS}_{\mathrm{commod}} 1\left(-1730 \mathrm{~kJ} \cdot \mathrm{mol}^{-1}\right)$ with those of the corresponding samples including siRNA carriers, i.e. NP- $\mathrm{CS}_{\mathrm{com}} \mathrm{P}\left(-150 \mathrm{~kJ}^{\mathrm{mol}} \mathrm{m}^{-1}\right)$ and NP- $\mathrm{CS}_{\text {com }}$ mod1P $\left(-510 \mathrm{~kJ} \cdot \mathrm{mol}^{-1}\right)$. A lower influence was also observed investigating interactions of siRNA with siRNA carriers prepared with chitosan acetate, NP-CS $\mathrm{Lab}_{\mathrm{P}} \mathrm{P}$ and NP- $\mathrm{CS}_{\mathrm{Com}}$-mod2P. Going further, it was recently pointed out that interactions between polyelectrolytes can be influenced when they take place in a confine environment [82]. Interactions of siRNA with our carrier occur in such conditions and the influence of the counterion on the thermodynamic aspects of interactions between siRNA and chitosan should also be considered regarding confinement found at the surface of nanoparticles. 


\section{Conclusion.}

Here, we have demonstrated that the shift of chitosan source for the preparation of a siRNA carrier can be problematic altering the quality of the formulation. Thus, the degree of deacetylation and molecular weight of chitosan are insufficient parameters to consider obtaining chitosan-based siRNA carriers having similar quality in terms of siRNA association when they are prepared with chitosan from different sources. The nature of the counterion associated with chitosan previously described as having only a marginal effect was shown here to influence interactions between siRNA and chitosan on the thermodynamic standpoint. The effect was interpreted from the lyotropic character of the counterion. This relates to the application of a different salting-out effect on chitosan chains depending on the nature of the counterion that can interfere with dehydration phenomena involved during interactions of chitosan with siRNA. Thus, the main conclusion of this work was that the nature of the salt of chitosan is another structural parameter of chitosan that should be considered while formulating chitosan-based delivery systems for siRNA. With this recommendation, this work opens perspectives to improve the rate of success of translation for the fabrication of clinical batches of chitosan-based delivery systems for siRNA. Besides, results and assumptions drawn from this work can serve as starting point to elucidate in-depth mechanisms by which counterions of chitosan interfere during the formation of siRNA-chitosan complexes. In complement, it would be interested to elucidate whether the nature of the counterion of chitosan would also interfere on thermodynamic aspects of interactions of chitosan with other nucleic acids and what would be the influence on the stability of the complexes and the releasing properties of the nucleic acids.

\section{Acknowledgements}

Financial support was obtained from INNABIOSANTE, Toulouse, France project NANOINTERFERENCE

\section{References}

1. Mello CC, Conte D Jr. Revealing the world of RNA interference. Nature. 2004;431(7006):338-42.

2. Carthew RW, Sontheimer EJ Origins and Mechanisms of miRNAs and siRNAs. Cell. 2009; 136(4): 642-655. doi: 10.1016/j.cell.2009.01.035

3. Ramon AL, Bertrand JR, Malvy C. Delivery of small interfering RNA. A review and an example of application to a junction oncogene. Tumori. 2008;94:254-263.

4. Strumberg D, Schultheis B, Traugott U, Vank C, Santel A, Keil O, Giese K, Kaufmann J, Drevs J. Phase I clinical development of Atu027, a siRNA formulation targeting PKN3 in patients with advanced solid tumors. Int J Clin Pharmacol Ther. 2012;50(1):76-78.

5. Lee MJ, Yoon TJ, Cho YS. Recent developments in nanoparticle-based siRNA delivery for cancer therapy. Biomed Res Int. 2013;2013:782041. doi : 10.1155/2013/782041.

6. Ozcan G, Ozpolat B, Coleman RL, Sood AK, Lopez-Berestein G. Preclinical and clinical development of siRNAbased therapeutics. Adv Drug Deliv Rev. 2015;87:108-19. doi: 10.1016/j.addr.2015.01.007.

7. Herrera VLM, Colby AH, Ruiz-Opazol N, Coleman DG, Grinstaff MW. Nucleic acid nanomedicines in Phase II/III clinical trials: translation of nucleic acid therapies for reprogramming cells. Nanomedicine (Lond). 2018;13(16):2083-2098. doi: 10.2217/nnm-2018-0122. 
8. Mahmoodi Chalbatani G, Dana H, Gharagouzloo E, Grijalvo S, Eritja R, Logsdon CD, Memari F, Miri SR, Rad MR, Marmari V. Small interfering RNAs (siRNAs) in cancer therapy: a nano-based approach. Int J Nanomedicine. 2019;14:3111-3128. doi: 10.2147/IJN.S200253.

9. Zhang E, Xing R, Liu S, Qin Y, Li K, Li P. Advances in chitosan-based nanoparticles for oncotherapy. Carbohydr Polym. 2019;222:115004. doi: 10.1016/j.carbpol.2019.115004.

10. Bruno K. Using drug-excipient interactions for siRNA delivery. Adv Drug Deliv Rev. 2011;63:1210-1226.

11. Dolina JS, Sung SS, Novobrantseva TI, Nguyen TM, Hahn YS. Lipidoid Nanoparticles Containing PD-L1 siRNA Delivered In Vivo Enter Kupffer Cells and Enhance NK and CD8(+) T Cell-mediated Hepatic Antiviral Immunity. Mol Ther Nucleic Acids. 2013;19(2):e72.

12. Forbes DC, Peppas NA. Oral delivery of small RNA and DNA. J Control Release. 2012;162:438-445.

13. Kole R, Leppert BJ. Targeting mRNA Splicing as a Potential Treatment for Duchenne Muscular Dystrophy. Discov Med. 2012;14:59-69.

14. Gomes MJ, Martins S, Sarmento B. siRNA as a tool to improve the treatment of brain diseases: Mechanism, targets and delivery. Ageing Res Rev. 2015;21:43-54. doi: 10.1016/j.arr.2015.03.001.

15. Christie RJ, Nishiyama N, Kataoka K. (2010). Minireview: Delivering the Code: Polyplex Carriers for Deoxyribonucleic Acid and Ribonucleic Acid Interference Therapies. Endocrinology. 2010;151:466-473.

16. Juliano RL. The delivery of therapeutic oligonucleotides. Nucleic Acids Res. 2016;44(14):6518-48. doi: 10.1093/nar/gkw236.

17. Costa DF, Torchilin VP. Micelle-like nanoparticles as siRNA and miRNA carriers for cancer therapy. Biomed Microdevices. 2018;20(3):59. doi: 10.1007/s10544-018-0298-0.

18. Cao Y, Tan YF, Wong YS, Liew MWJ, Venkatraman S. Recent Advances in Chitosan-Based Carriers for Gene Delivery. Mar Drugs. 2019;17(6). pii: E381. doi: 10.3390/md17060381..

19. De Martimprey H, Vauthier C, Malvy C, Couvreur P. Polymer nanocarriers for the delivery of small fragments of nucleic acids: Oligonucleotides and siRNA. Eur J Pharm Biopharm. 2009;71:490-504.

20. Howard KA. Delivery of RNA interference therapeutics using polycation-based nanoparticles. Adv Drug Deliv Rev. 2009;61:710-20.

21. Mao S, Sun W, Kissel T. Chitosan-based formulations for delivery of DNA and siRNA. Adv Drug Del. Rev. 2010;62:12-27.

22. Rudzinski WE, Aminabhavi TM. Chitosan as a carrier for targeted delivery of small interfering RNA. Int J Pharm. 2011;399:1-11. doi:10.1016/j.ijpharm.2010.08.022.

23. Singha K, Namgung R, Kim WJ. Polymers in Small-Interfering RNA Delivery. Nuc Ac Therap. 2011;21:133-147.

24. Al-Qadi S, Grenha A, Remunan-Lopez C. Chitosan and its derivatives as nanocarriers for siRNA delivery. J Drug Del Sci Technol. 2012;22:29-42.

25. Rodrigues S, Dioniso M, Remunan-Lopez C, Grenha A. Biocompatibility of chitosan carriers with applications in drug delivery. J Funct Biomater. 2012;3:615-641.

26. Buschmann MD, Merzouki A, Lavertu M, Thibault M, Jean M, Darras V. Chitosans for delivery of nucleic acids. Adv Drug Deliv Rev. 2013;65(9):1234-70. doi: 10.1016/j.addr.2013.07.005.

27. Kanasty R, Dorkin JR, Arturo Vegas A, Anderson D. Delivery materials for siRNA therapeutics, Nat Mater. 2013;12: 967-977.

28. Vauthier C, Zandanel C, Ramon AL. Chitosan-based nanoparticles for in vivo delivery of interfering agents including siRNA. Curr Opin Coll Interf Sci. 2013;18:406-418. doi: 10.10106/j.cocis.2013.06.005. 
29. Ragelle H, Vendermeulen G, Préat V. Chitosan-based siRNA delivery systems. J Contr Rel. 2013;172:207-218. doi: 10.1016/j.jconrel.2013.08.005.

30. Bravo-Anaya LM, Soltero JFA, Rinaudo M. DNA/chitosan electrostatic complex. Int J Biol Macromol. 2016;88:345-353

31. Cavallaro G, Sardo C, Craparo EF, Porsio B, Giammona G. Polymeric nanoparticles for siRNA delivery: Production and applications. Int J Pharm. 2017;525(2):313-333. doi: 10.1016/j.ijpharm.2017.04.008.

32. Huh MS, Lee EJ, Koo H, Yhee JY, Oh KS, Son S, Lee S, Kim SH, Kwon IC, Kim K. Polysaccharide-based Nanoparticles for Gene Delivery. Top Curr Chem (Cham). 2017;375(2):31. doi: 10.1007/s41061-017-0114-y.

33. Serrano-Sevilla I, Artiga Á, Mitchell SG, De Matteis L, de la Fuente JM. Natural Polysaccharides for siRNA Delivery: Nanocarriers Based on Chitosan, Hyaluronic Acid, and Their Derivatives. Molecules. 2019;24(14). pii: E2570. doi: 10.3390/molecules24142570.

34. Xu S, Dong M, Liu X, Howard KA, Kjems,J, Besenbacher F. Direct Force Measurements between siRNA and Chitosan Molecules Using Force Spectroscopy. Biophys J. 2007; 93:952-959.

35. Ma PL, Lavertu M, Winnik FM, Buschmann MD. New Insights into Chitosan-DNA Interactions Using Isothermal Titration Microcalorimetry. Biomacromol. 2009;10:1490-1499.

36. Huang M, Khor E, Lim LY. Uptake and Cytotoxicity of Chitosan Molecules and Nanoparticles: Effects of Molecular Weight and Degree of Deacetylation. Pharm Res. 2004;21:344-353.

37. Alameh M, Lavertu M, Tran-Khanh N, Chang CY, Lesage F, Bail M, Darras V, Chevrier A, Buschmann MD. siRNA Delivery with Chitosan: Influence of Chitosan Molecular Weight, Degree of Deacetylation, and Amine to Phosphate Ratio on in Vitro Silencing Efficiency, Hemocompatibility, Biodistribution, and in Vivo Efficacy. Biomacromolecules. 2018; 19(1):112-131. doi: 10.1021/acs.biomac.7b01297. Epub 2017 Dec 28.

38. Delas T, Mock-Joubert M, Faivre J, Hofmaier M, Sandre O, Dole F, Chapel JP, Crépet A, Trombotto S, Delair T, Schatz C. Effects of Chain Length of Chitosan Oligosaccharides on Solution Properties and Complexation with siRNA. Polymers (Basel). 2019;11(8). pii: E1236. doi: 10.3390/polym11081236.

39. Kiang T, Wen J, Lim HW, Leong KW. The effect of the degree of chitosan deacetylation on the efficiency of gene transfection. Biomaterials. 2004;25:5293-5301.

40. Techaarpornkul S, Wongkupasert S, Opanasopit P, Apirakaramwong A, Nunthanid J, Ruktanonchai U. Chitosan-Mediated siRNA Delivery In Vitro: Effect of Polymer Molecular Weight, Concentration and Salt Forms AAPS PharmSciTech. 2010; 11(1): 64-72. Published online 2010 Jan 8. doi: 10.1208/s12249-009-9355-6

41. Kumirska J, Weinhold MX, Thöming J, Stepnowski P. Biomedical Activity of Chitin/Chitosan Based MaterialsInfluence of Physicochemical Properties Apart from Molecular Weight and Degree of N-Acetylation. Polymers. 2011;3(4):1875-1901; DOI: 10.3390/polym3041875.

42. Yang C, Gao S, Dagnæs-Hansen F, Jakobsen M, Kjems J. Impact of PEG Chain Length on the Physical Properties and Bioactivity of PEGylated Chitosan/siRNA Nanoparticles in Vitro and in Vivo. ACS Appl Mater Interfaces. 2017;9(14):12203-12216. doi: 10.1021/acsami.6b16556

43. De Martimprey H, Bertrand JR, Malvy C, Couvreur P, Vauthier C. New Core-Shell Nanoparticules for the Intravenous Delivery of siRNA to Experimental Thyroid Papillary Carcinoma. Pharm Res. 2010;27:498-509.

44. Ramon AL, Bertrand JR, De Martimprey H, Bernard G, Ponchel G, Malvy C, Vauthier C. SiRNA associated with immunonanoparticles directed against cd99 antigen improve gene expression inhibition in vivo in Ewing's sarcoma. J Mol Recognit. 2013;26:318-329.

45. Gaudin A, Andrieux K, Couvreur P. Nanomedicines and stokes: towards translational research. J Drug Deliv Sci Technol. 2015;30:278-299.

46. Lakkireddy HR, Bazile D. Building the design, translation and development principles of polymeric nanomedicines using the case of clinically advanced poly(lactide(glycolide))-poly(ethylene glycol) 
nanotechnology as a model: An industrial viewpoint. Adv Drug Deliv Rev. 2016;107:289-332. doi: 10.1016/j.addr.2016.08.012.

47. Lakkireddy HR, Bazile D. Nano-carriers for drug routeing - towards a new era. J Drug Target. 2019;27(5-6):525541. doi: 10.1080/1061186X.2018.1561891.

48. Satalkar P, Elger BS, Hunziker P, Shaw D. Challenges of clinical translation in nanomedicine: A qualitative study. Nanomedicine. 2016;12(4):893-900. doi: 10.1016/j.nano.2015.12.376.

49. Agrahari V, Hiremath P. Challenges associated and approaches for successful translation of nanomedicines into commercial products. Nanomedicine (Lond). 2017;12(8):819-823. doi: 10.2217/nnm-2017-0039.

50 Anchordoquy TJ, Barenholz Y, Boraschi D, Chorny M, Decuzzi P, Dobrovolskaia MA, Farhangrazi ZS, Farrell D, Gabizon A, Ghandehari H, Godin B, La-Beck NM, Ljubimova J, Moghimi SM, Pagliaro L, Park JH, Peer D, Ruoslahti E, Serkova NJ, Simberg D. Mechanisms and Barriers in Cancer Nanomedicine: Addressing Challenges, Looking for Solutions. ACS Nano. 2017;11(1):12-18. doi: 10.1021/acsnano.6b08244.

51. Hua S, de Matos MBC, Metselaar JM, Storm G. Current Trends and Challenges in the Clinical Translation of Nanoparticulate Nanomedicines: Pathways for Translational Development and Commercialization. Front Pharmacol. 2018;9:790. doi: 10.3389/fphar.2018.00790. Clinical translation

52. Dormont F, Rouquette M, Mahatsekake C, Gobeaux F, Peramo A, Brusini R, Calet S, Testard F, LepetreMouelhi S, Desmaële D, Varna M, Couvreur P. Translation of nanomedicines from lab to industrial scale synthesis: The case of squalene-adenosine nanoparticles. J Control Release. 2019;307:302-314. doi: 10.1016/j.jconrel.2019.06.040.

53. Soma E, Attali P, Merle P. A clinically relevant case study: the development of Livatag ${ }^{\circledR}$ for the treatment of advanced hepatocellular carcinoma. In: Alonso MJ, Csaba NS, editors. RSC Drug Discovery Series $N^{\circ} 22$ : Nanostructured Biomaterials for Overcoming Biological Barriers. Dorchester (UK): The Royal Society of Chemistry; 2012, p 591-600. doi: 10.1039/9781849735292-00591.

54. Merle P, Pelletier G, Habersetzer F, Luca Frassineti G, Pageaux GP, Borbath I, Gérolami R, Sánchez Antolin G, Bronowicki JP, Horváth Z, Touchefeu Y, Maieron A, Wege H, Breder V, Gabrail N, Vasseur B, Attali P, Blanc JF. A multicentre, randomised, open-label study comparing the efficacy and safety of two doses of Doxorubicin Transdrug $^{\mathrm{TM}}$ to best standard of care in patients with advanced Hepatocellular Carcinoma (HCC) after sorafenib. The relive study. P1334 J. Hepatology 2015;62(Supp. 2):S856. doi:10.1016/S0168-8278(15)31513-0.

55. Merle P, Camus P, Abergel A, Pageaux GP, Masliah C, Bronowicki JP, Zarski JP, Pelletier G, Bouattour M, Farloux L, Dorval E, Verset G, Si-Ahmed SN, Doffoel M, Couzigou P, Taieb J, Vasseur B, Attali P. Safety and efficacy of intra-arterial hepatic chemotherapy with doxorubicin-loaded nanoparticles in hepatocellular carcinoma. ESMO Open. 2017;2(4):e000238. doi:10.1136/esmoopen-2017-000238.

56. Rinaudo M. Chitin and chitosan: Properties and applications. Prog Polymer Sci. 2006;31:603-632.

57. Domard A. A perspective on 30 years research on chitin and chitosan. Carbohydrate Polymers. 2011;84: 696703. DOI: $10.1016 /$ j.carbpol.2010.04.083.

58. Liu X, Howard KA, Dong M, Andersen M $\varnothing$, Rahbek UL, Johnsen MG, Hansen OC, Besenbacher F, Kjems J. The influence of polymeric properties on chitosan/siRNA nanoparticle formulation and gene silencing. Biomaterials. 2007;28:1280-1288.

59. Holzerny P, Ajdini B, Heusermann W, Bruno K, Schuleit M, Meinel L, Keller M. Biophysical properties of chitosan/siRNA polyplexes: Profiling the polymer/siRNA interactions and bioactivity. J Control Release. 2012;157:297-304. doi:10.1016/j.jconrel.2011.08.023.

60. Bravo-Anaya LM, Fernández-Solís KG, Rosselgong J, Nano-Rodríguez JLE, Carvajal F, Rinaudo M. Chitosan-DNA polyelectrolyte complex: influence of chitosa characteristics and mechanism of complex formation. Int J Biol Macromol. 2019;126:1037-1049. 
61. Katas H, Alpar HO. Development and characterization of chitosan nanoparticles for siRNA delivery. J Control Rel. 2006;115:216-225.

62. Weecharangsan W, Opanasopit P, Ngawhirunpart T, Apirakaramwong A, Rojanarata T, Ruktanonchai U, Lee RJ. Evaluation of chitosan salts as non-viral gene vectors in CHO-K1 cells. Int J Pharm. 2008;348:161-168.

63. Patel HR, Patel SP, Patel MM. Poloxamers: A pharmaceutical excipients with therapeutic behaviors. Int J Pharm Tech Res. 2009;1(2):299-303.

64. Poloxamer 188 Drug Bank \#DB11333. 2019 September 17. Available from: https://www.drugbank.ca/drugs/DB11333.

65. Bertholon I, Lesieur S, Labarre D, Besnard M, Vauthier C. Characterization of Dextran-Poly(isobutylcyanoacrylate) Copolymers Obtained by Redox Radical and Anionic Emulsion Polymerization. Macromolecules. 2006;39:3559-3567.

66. Maghami GG, Roberts GAF. Evaluation of the viscometric constants for chitosan. Makromol Chem. 1988;189:195-200.

67. Khan TA, Peh KK, Ch'ng HS. Mechanical, bioadhesive strength and biological evaluations of chitosan films for wound dressing. J Pharm Pharm Sci. 2000;3(3):303-11.

68. Hirai A; Odani H, Nakajima A. Determination of degree of deacetylation of chitosan by ${ }^{1} \mathrm{H}$ NMR spectroscopy. Polym Bull. $1991 ; 26: 87-94$.

69. Zandanel C, Vauthier C. Poly(isobutylcyanoacrylate) Nanoparticles Decorated with Chitosan: Effect of Conformation of Chitosan Chains at the Surface on Complement Activation Properties. J Colloid Sci Biotechnol. 2012;1, 68-81.

70. Vauthier C, Schmidt C, Couveur P. Measurement of the Density of Polymeric Nanoparticulate Drug Carriers by Isopycnic Centrifugation. J Nanopart Res. 1999;1:411-418.

71. Ma PL, Lavertu M, Winnik FM, Buschmann MD. Stability and binding affinity of DNA/chitosan complexes by polyanion competition. Carbohydr Polym. 2017;176:167-176. doi: 10.1016/j.carbpol.2017.08.002.

72. Zhang Y, Cremer PS. Interactions between macromolecules and ions: The Hofmeister series. Curr Opin Chem Biol. 2006;10(6):658-663. Doi: 10.1016/j.cbpa.2006.09.020

73. Song W, Liu L, Liu G. Ion specificity of macromolecules in crowded environments. Soft Matter. 2015;11:59405946.

74. Okur HI, Hladílková J, Rembert KB, Cho Y, Heyda J, Dzubiella J, Cremer PS, Jungwirth P. Beyond the Hofmeister Series: Ion-Specific Effects on Proteins and Their Biological Functions. J Phys Chem B. 2017;121(9):1997-2014. doi: $10.1021 /$ acs.jpcb.6b10797.

75. Zhang Y, Furyk S, Bergbreiter DE, Cremer PS. Specific Ion Effects on the Water Solubility of Macromolecules: PNIPAM and the Hofmeister Series. J Am Chem Soc. 2005;127:14505-14510. DOI: 10.1021/ja054642

76. Mrácek A, Varhaníková J, Lehocký M, Grundelová L, Pokopcová A, Velebný V. The influence of Hofmeister series ions on hyaluronan swelling and viscosity. Molecules. 2008;13(5):1025-34.

77. Zajforoushan Moghaddam S, Thormann E. Hofmeister effect of salt mixtures on thermo-responsive poly(propylene oxide). Phys Chem Chem Phys. 2015;17(9):6359-66

78. Zajforoushan Moghaddam S, Thormann E. Hofmeister Effect on PNIPAM in Bulk and at an Interface: Surface Partitioning of Weakly Hydrated Anions. Langmuir. 2017;33(19):4806-4815. doi: 10.1021/acs.langmuir.7b00953

79. Chen WY, Hsu MY, Tsai CW, Chang Y, Ruaan RC, Kao WH, Huang EW, Chuan HY. Kosmotrope-like hydration behavior of polyethylene glycol from microcalorimetry and binding isotherm measurements. Langmuir. 2013;29(13):4259-65. doi: 10.1021/la304500w. 
80. Smith MH, Lyon LA. Multifunctional nanogels for siRNA delivery. Acc Chem Res. 2012;45(7):985-993. doi: 10.1021/ar200216f. Poly(NIPAM) siRNA delivery

81. Yang HY, van Ee RJ, Timmer K, Craenmehr EGM, Huang JH, Öner FC, Dhert WJA, Kragten AHM, Willems N, Grinwis GCM, Tryfonidou MA, Papen-Botterhuis NE, Creemers LB. A novel injectable thermoresponsive and cytocompatible gel of poly( $\mathrm{N}$-isopropylacrylamide) with layered double hydroxides facilitates siRNA delivery into chondrocytes in 3D culture. Acta Biomater. 2015;23:214-228. doi: 10.1016/j.actbio.2015.05.018.

82. Antila HS, Van Tassel PR, Sammalkorpi M. Repulsion between oppositely charged rod-shaped macromolecules: Role of overcharging and ionic confinement. J Chem Phys. 2017;147(12):124901. doi: 10.1063/1.4993492. 